\title{
Size distribution, mass concentration, chemical and mineralogical composition and derived optical parameters of the boundary layer aerosol at Tinfou, Morocco, during SAMUM 2006
}

\author{
By K. KANDLER ${ }^{1 *}, \mathrm{~L} . \mathrm{SCHÜTZ}^{2}, \mathrm{C} . \mathrm{DEUTSCHER}^{2}, \mathrm{M} . \mathrm{EBERT}^{1}, \mathrm{H} . \mathrm{HOFMANN}^{1}$, \\ S. JÄCKEL ${ }^{1}$, R. JAENICKE ${ }^{2}$, P. KNIPPERTZ ${ }^{2}, K_{\text {. LIEKE }}{ }^{1}, A$. M ASSLING $^{3}, A$. PETZOLD $^{4}$, \\ A. SCHLADITZ ${ }^{3}$, B. WEINZIERL ${ }^{4}$, A. WIEDENSOHLER ${ }^{3}$, S. ZORN $^{2}$ and S. WEINBRUCH ${ }^{1}$, \\ ${ }^{1}$ Institut für Angewandte Geowissenschaften, Technische Universität Darmstadt, Schnittspahnstr. 9, 64287 Darmstadt, \\ Germany; ${ }^{2}$ Institute für Physik der Atmosphäre, Johannes-Gutenberg-Universität, J.-J.-Becherweg 21, 55099 Mainz, \\ Germany; ${ }^{3}$ Leibniz-Institut für Troposphärenforschung, Permoserstr. 15, 04318 Leipzig, Germany; ${ }^{4}$ Institut für Physik \\ der Atmosphäre, Deutsches Zentrum für Luft- und Raumfahrt (DLR), Oberpfaffenhofen, 82234 Wessling, Germany
}

(Manuscript received 28 December 2007; in final form 28 July 2008)

\begin{abstract}
During the SAMUM 2006 field campaign in southern Morocco, physical and chemical properties of desert aerosols were measured. Mass concentrations ranging from $30 \mu \mathrm{g} \mathrm{m}^{-3}$ for $\mathrm{PM}_{2.5}$ under desert background conditions up to $300000 \mu \mathrm{g} \mathrm{m}^{-3}$ for total suspended particles (TSP) during moderate dust storms were measured. TSP dust concentrations are correlated with the local wind speed, whereas $\mathrm{PM}_{10}$ and $\mathrm{PM}_{2.5}$ concentrations are determined by advection from distant sources. Size distributions were measured for particles with diameter between $20 \mathrm{~nm}$ and $500 \mu \mathrm{m}$ (parametrizations are given). Two major regimes of the size spectrum can be distinguished. For particles smaller than $500 \mathrm{~nm}$ diameter, the distributions show maxima around $80 \mathrm{~nm}$, widely unaffected of varying meteorological and dust emission conditions. For particles larger than $500 \mathrm{~nm}$, the range of variation may be up to one order of magnitude and up to three orders of magnitude for particles larger than $10 \mu \mathrm{m}$. The mineralogical composition of aerosol bulk samples was measured by X-ray powder diffraction. Major constituents of the aerosol are quartz, potassium feldspar, plagioclase, calcite, hematite and the clay minerals illite, kaolinite and chlorite. A small temporal variability of the bulk mineralogical composition was encountered. The chemical composition of approximately 74000 particles was determined by electron microscopic single particle analysis. Three size regimes are identified: for smaller than $500 \mathrm{~nm}$ in diameter, the aerosol consists of sulphates and mineral dust. For larger than $500 \mathrm{~nm}$ up to $50 \mu \mathrm{m}$, mineral dust dominates, consisting mainly of silicates, and-to a lesser extent—carbonates and quartz. For diameters larger than $50 \mu \mathrm{m}$, approximately half of the particles consist of quartz. Time series of the elemental composition show a moderate temporal variability of the major compounds. Calcium-dominated particles are enhanced during advection from a prominent dust source in Northern Africa (Chott El Djerid and surroundings). The particle aspect ratio was measured for all analysed particles. Its size dependence reflects that of the chemical composition. For larger than $500 \mathrm{~nm}$ particle diameter, a median aspect ratio of 1.6 is measured. Towards smaller particles, it decreases to about 1.3 (parametrizations are given). From the chemical/mineralogical composition, the aerosol complex refractive index was determined for several wavelengths from ultraviolet to near-infrared. Both real and imaginary parts show lower values for particles smaller than $500 \mathrm{~nm}$ in diameter $\left(1.55-2.8 \times 10^{-3} \mathrm{i}\right.$ at $\left.530 \mathrm{~nm}\right)$ and slightly higher values for larger particles $\left(1.57-3.7 \times 10^{-3} \mathrm{i}\right.$ at $\left.530 \mathrm{~nm}\right)$.
\end{abstract}

\footnotetext{
*Corresponding author.

\section{Introduction}

Long-range transport of mineral dust influences the climatic system directly and indirectly (e.g. Levin et al., 1996; Tegen et al., 1996; Haywood and Boucher, 2000), as well as atmospheric chemistry (e.g. Bauer et al., 2004; Matsuki et al., 2005; Rastogi and Sarin, 2006; Jeong and Sokolik, 2007; Sullivan et al., 
2007). The omnipresence of dust causes a direct radiative forcing, but the magnitude - its sign and its global significance-is actually discussed (e.g. Jacobson, 2001 and references therein; Balkanski et al., 2007). Dust from the Saharan desert contributes significantly to the global dust burden (Kaufman et al., 2005). Physical properties of the mineral dust as well as its chemical and mineralogical composition and state of mixing change its influence on climate and atmospheric chemistry (Dentener et al., 1996; Sokolik et al., 2001; Lesins et al., 2002; Helmert et al., 2007; Jeong and Sokolik, 2007).

The Saharan Mineral Dust Experiment (SAMUM) is dedicated to the understanding of the radiative effects of mineral dust in a major source region (Heintzenberg, 2008). A first joint field campaign was performed from 13 May to 7 June 2006 in southern Morocco. Coordinated aircraft and ground based measurements were carried out. An experimental data set of surface and atmospheric columnar information was collected. This data set, combined with satellite data, will provide the basis of the first thorough columnar radiative closure tests in Saharan dust. During the course of this campaign, a variety of aerosol physical and chemical properties were measured. In the present paper, mass concentrations and size distributions will be presented, as well as data of the size-resolved mineral and chemical composition of the dust in the boundary layer. From this data set, optical parameters can be derived, which are important input parameters for any radiative transfer calculations to be carried out by other project partners of the SAMUM consortium. Dust physical and chemical parameters, like the size distribution, mineral phases, shape and complex refractive indices, for example, cannot be implemented from the existing literature, as these data are originating from different locations, seasons, meteorological and surface morphological conditions. In addition, such parameters vary strongly in space and time, they are non-uniform over the size and wavelength spectrum and depend on the local sources and transport from distant sources. Therefore, a closure experiment was necessary to characterize the whole atmospheric column from the ground up to the top of the atmosphere.

\section{Location}

The field experiment took place in the northwestern part of Africa (Fig. 1). For technical reasons, the aircraft and Lidar activities of the SAMUM consortium were concentrated at the airports of Casablanca and Ouarzazate. The latter one is located at the southern foothills of the High Atlas range in the northern Drâa valley. However, the boundary layer aerosol measuring and sampling site was erected close to the hotel 'Porte au Sahara' near the village of Dunes du Tinfou (Fig. 1), which is located $35 \mathrm{~km}$ southeast of the city Zagora in the province of Zagora in southern Morocco $\left(30^{\circ} 14^{\prime} 15^{\prime \prime} \mathrm{N}, 5^{\circ} 36^{\prime} 29^{\prime \prime} \mathrm{W}, 684 \mathrm{~m}\right.$ a.s.1.).

This location is situated on the Drâa river flood plains (Fig. 1, small map); it is divided from the western Algerian plains by a mountain chain (Jbel Tadrat and Jbel Bani) that raises approximately $500 \mathrm{~m}$ above the Drâa river plains, at a distance of more than $10 \mathrm{~km}$ from the station. The Drâa river flows from the High Atlas mountains southeastward to Tagounite and
Fig. 1. Northwestern Africa and the Atlas mountain range in Morocco. The detail map shows the region of the Tinfou ground station.

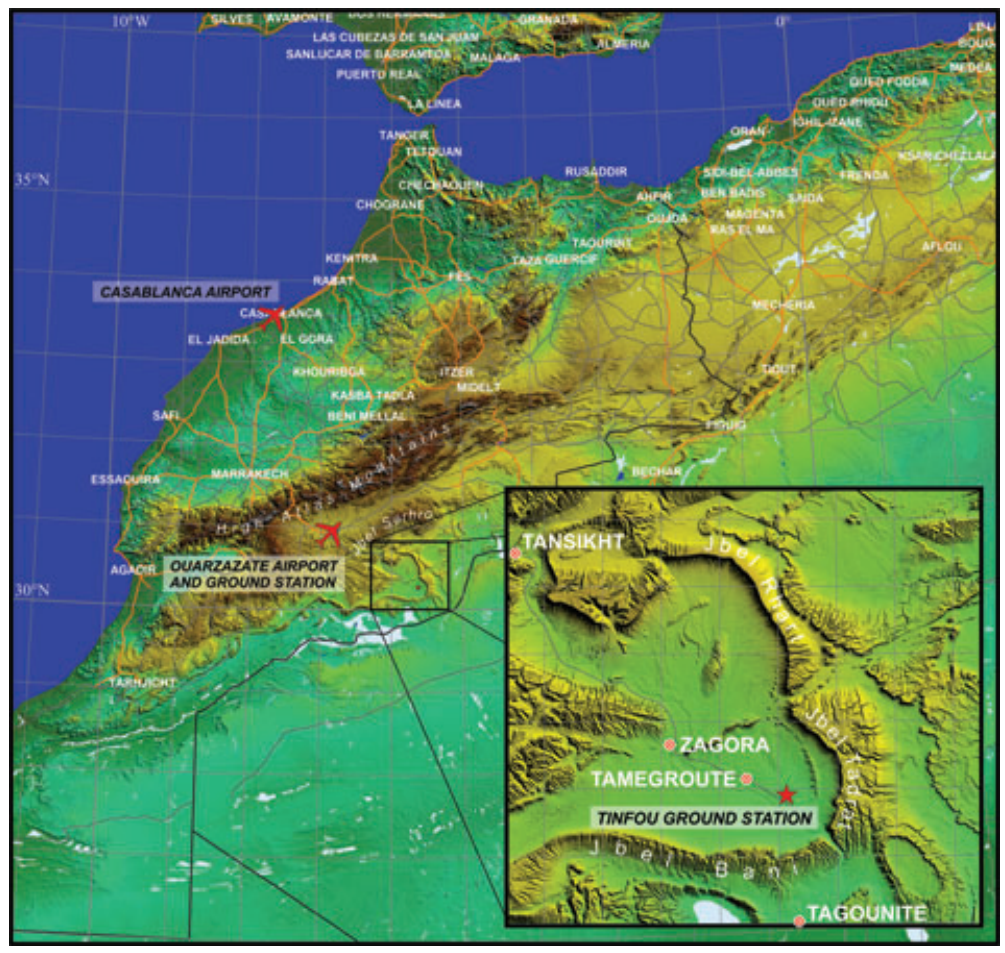


finally westwards to the Atlantic Ocean. Most of the year the Drâa river falls dry in the southern parts of the valley. This area southeast of the High Atlas mountains and the Jbel Sarhro range is the border of the Saharan desert, which extends from the Drâa region about $1500 \mathrm{~km}$ in southerly directions to the Sahel region. According to the Köppen climate classification, to the temperature and humidity distribution and to the extreme variability of precipitation (Warner, 2004), the region can be considered as part of the Saharan desert with airborne dust being frequently observed during summer.

From commercial aircraft observations, it can be concluded that a dust layer well extending over the lower troposphere can be found regularly in this region. This is supported by measurements carried out during the Lidar In-space Technology Experiment (LITE) 1994. Backscatter transects over northwestern Africa indicated that the Saharan Air Layer is present in the region south of the High Atlas Mountains and extends into altitudes up to $5 \mathrm{~km}$. The LITE Level $1532 \mathrm{~nm}$ profile data over the Sahara during orbit 146 at approximately 23 GMT on 18 September 1994 (Winker et al., 1996) is a typical example of an orbit transect over the Atlas Mountain range near $31^{\circ} \mathrm{N}, 8^{\circ} \mathrm{W}$, where the mountain range approximately separates a more optically thick aerosol air mass in the southeast from a relatively cleaner air mass in the northwest.

The frequent presence of dust due to advection of Saharan air was also confirmed by air mass trajectory calculations. Air backtrajectory calculations were made for Zagora $\left(30^{\circ} 18^{\prime} \mathrm{N}, 5^{\circ} 34^{\prime} \mathrm{W}\right)$ with the HYSPLIT4 model (Draxler and Hess, 1998) for 6 years (1997 to 2002) based on the FNL data set (Rutledge et al., 2006). The results in Fig. 2 clearly show that air masses over the Drâa valley originate in $50 \%$ of the year from the Saharan desert in altitudes up to $2500 \mathrm{~m}$.

The local wind situation at the measurement location (Fig. 3) reflects the trajectory analysis of prevailing easterly winds. Local

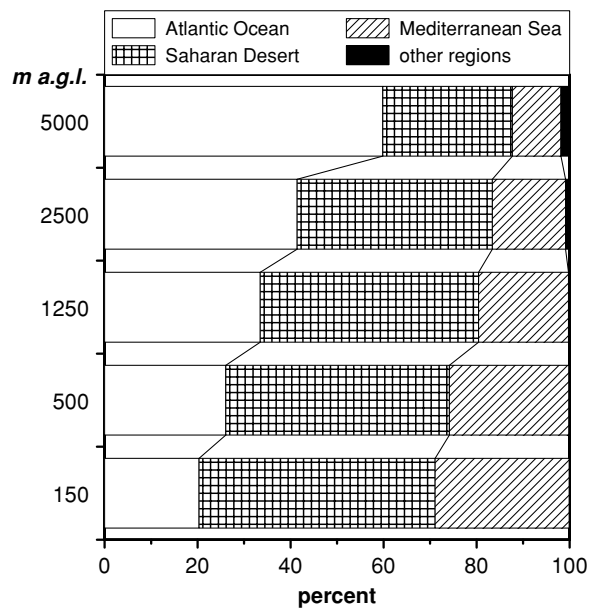

Fig. 2. Six-year air mass backtrajectory calculations as a function of altitude for Zagora (position of the air between $25 \mathrm{~h}$ and $48 \mathrm{~h}$ before arrival).

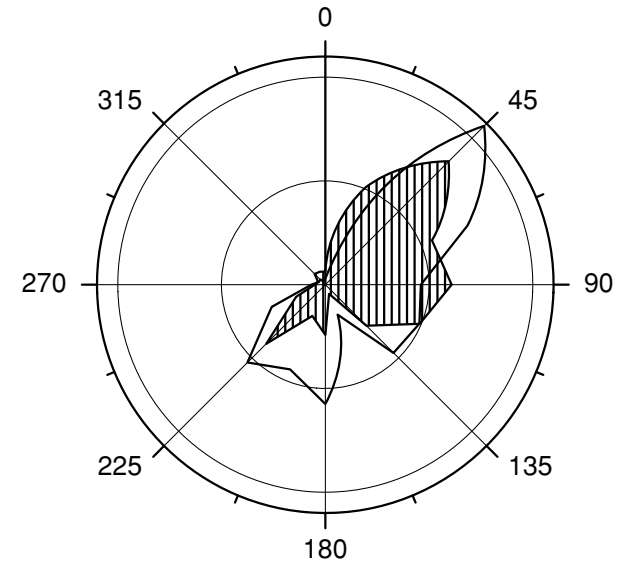

Fig. 3. Local daytime (white) and nighttime (shaded) time-integrated wind speed for the measurement campaign at Tinfou.

advection from westerly directions occurred very rarely during the campaign. A diurnal pattern exists in the wind situation, probably triggered by the radiation heating of the surrounding mountain ranges.

\subsection{Aircraft measurements}

Measurements were performed onboard of two aircrafts, the 'Falcon' (Weinzierl et al., 2008) and the 'Partenavia' (Type P68B, based on the airport of Ouarzazate, Morocco). Onboard the Falcon, sampling for single particle analysis was performed with a set of MINI impactors (Kandler et al., 2007). A nearisokinetic inlet was mounted outside the boundary layer of the Falcon aircraft to avoid a disturbance of the sampled air by the aircraft fuselage. A diffuser was used to decelerate the air flow entering the cabin. 50\% transmission efficiency was calculated for particles of $2.5 \mu \mathrm{m}$ diameter at surface pressure and $1.5 \mu \mathrm{m}$ at $10-\mathrm{km}$ altitude. Onboard the Partenavia, the Mobile Cascade Impaction System MOCIS was used, which is described in detail by Matthias-Maser (1999) and Zorn (2005).

\section{Sampling and analysis}

The inlets of all sampling devices at Tinfou ground station were located approximately $4 \mathrm{~m}$ above ground and $1.5 \mathrm{~m}$ above the roof of the measurement container.

\subsection{Mass concentrations}

Mass concentrations (total suspended particulate matter (TSP), $\mathrm{PM}_{10}$ and $\mathrm{PM}_{2.5}$ equivalent) were determined gravimetrically from a suite of fibre filter samples, by means of a microbalance.

TSP samples were collected with a filter holder system operated quasi-isokinetically. Such a device consists of a $70 \mathrm{~mm}$ filter holder (glass fibre filter, MN GF-5, Macherey \& Nagel, 
Düren, Germany) on top of a wind vane that includes the vacuum supply for operation. Isoaxial sampling was possible with this design. Intake nozzles of different aperture sizes were used to adapt the intake velocity to the actual wind speed to enable an aspiration efficiency close to one, according to the criterion of Belyaev and Levin (1972).

The $\mathrm{PM}_{10}$ and $\mathrm{PM}_{2.5}$ samples were collected with two filter sampler devices, each consisting of a double slit impactor intake stage and a backup filter for sampling. The impactor stage is constructed according to the usual guidelines (Marple and Willeke, 1976) for rectangular jet impactors and Reynolds numbers of 3000 and operated with flow rates of approximately $8 \mathrm{~m}^{3} \mathrm{~h}^{-1}$ (50\% cut-off size of $2.5 \mu \mathrm{m}$ and $10 \mu \mathrm{m}$ aerodynamic diameter, respectively). A rotating drum covered with an adhesive acts as collection surface to provide several hours of high sampling efficiency without any bounce-off or blow-off, even under very dusty sampling conditions.

\subsection{Size distributions}

The size distributions presented in this work cover a total size range of $20 \mathrm{~nm}$ up to $500 \mu \mathrm{m}$ in particle diameter. They are composites of four measurement devices. Particularly the analysis in the supermicron range is very time-consuming. Thus, only one measurement per day (of approximately $30 \mathrm{~min}$. duration) was performed during the field campaign.

3.2.1. Size distributions in the sub-micron range. Size distributions were measured quasi-continuously by a combination of a Differential Mobility Particle Sizer (DMPS) for the mobility size range of 20-800 nm and an Aerodynamic Particle Sizer (APS; model 3321, TSI Inc., St. Paul, USA) for the aerodynamic size range of $850 \mathrm{~nm}$ to $5 \mu \mathrm{m}$. For details of measurement and data processing refer to Schladitz et al. (2008).

3.2.2. Size distributions in the supermicron range. For the size distribution measurements in the range of 4-500 $\mu \mathrm{m}$, particles were collected from the air by a single-stage impactor on glass substrates coated by silicon oil and a free-rotating wing impactor (Jaenicke and Junge, 1967). Both devices were aligned isoaxially to the wind direction by wind vanes. The single-stage impactor was used with deceleration nozzles to adapt the inlet flow speed to the wind speed. The impactor is a rectangular nozzle impactor with nozzle dimensions of $2 \mathrm{~mm} \times 20 \mathrm{~mm}$ and a volume air flow of approximately $1.7 \mathrm{~m}^{3} \mathrm{~h}^{-1}$. This yields a $50 \%$ efficiency cut-off of $2.3 \mu \mathrm{m}$. The sampling volume for the singlestage impactor-flow-fixed by a critical nozzle-was measured by a mass flow meter (Mass-Stream D-6250, Bronkhorst Mättig, Unna, Germany) and corrected to geometrical volume for pressure and temperature. Sampling volume ranged from 1.7 to $100 \mathrm{~L}$ with a median of $50 \mathrm{~L}$. As the free-rotating wing impactor is a body impactor, aspiration and transmission losses during sampling — which are critical for particles much larger than $20 \mu \mathrm{m}$-are avoided. The collection plates of the free- rotating wing impactor were $4 \mathrm{~cm} \times 5 \mathrm{~cm}$, the path diameter $60 \mathrm{~cm}$ and the rotation speed $6 \mathrm{~s}^{-1}$. This yields $50 \%$ sampling efficiency at approximately $17 \mu \mathrm{m}$ particle diameter at $12 \mathrm{~m} \mathrm{~s}^{-1}$ impact speed. The angle of the collection plates was adjusted to the wind speed measured at the beginning of the sampling period to maintain an orthogonal angle of attack on the aerosol. The sampling volume of the free-rotating wing impactor was determined as the geometrical skimming volume of the sampling plates. Depending on aerosol concentration, it ranged between 8 and $1250 \mathrm{~L}$, typically $700 \mathrm{~L}$.

Instantly after collection, the samples were placed in an optical microscope (Orthoplan, Leitz, Wetzlar, Germany) with darkfield setting. For the single-stage impactor, two or three stripes of $850 \mu \mathrm{m}$ width—consisting of adjacent rectangles of $850 \mu \mathrm{m} \times$ $640 \mu \mathrm{m}$ dimension — placed orthogonally to the impaction nozzle were analysed. For the free-rotating wing impactor, between 20 and 50 rectangles of $2150 \mu \mathrm{m} \times 1600 \mu \mathrm{m}$ dimension were analysed, distributed evenly across the sample. An image of each area was taken with a digital still camera (Camedia C5060WZ, Olympus Deutschland GmbH, Hamburg, Gemany) at a focal length of $23 \mathrm{~mm}$, a resolution of $2592 \times 1944$ pixels and the lowest possible sensitivity setting (to minimize electronic noise). The software package IMAGEJ (Rasband, 2006) was used for image processing and analysis. First, the images were corrected for uneven illumination. Afterwards, they were transformed into binary bitmaps using the maximum entropy threshold algorithm. Finally, the particles and their geometrical properties were measured. The particle volume was calculated by assuming the unknown height of the particle to be equal to the smallest diameter of an ellipse fitted to the particle outline, following the approach of Andersen et al. (1996):

$d=2\left(B \pi^{-1}\right)^{1 / 2} A R^{-1 / 6}$,

where $B$ is the area of the particle in the optical microscope and $A R$ the aspect ratio of an ellipse fitted to the particle outline. It could be suspected that the size of clay minerals derived by this approach is systematically too high, as sheet silicates tend to lay flat on the substrate. However, this is not the case in our samples, as the clay particles are mainly present as large aggregates, which do not have a platy morphology.

For technical reasons, it was impossible to mount both samplers at the same location. Thus, the absolute concentrations of both measured size distributions were adjusted by a constant factor to their geometrical mean, which was calculated in the overlapping region (14 to $57 \mu \mathrm{m}$ particle diameter).

To derive the atmospheric size distribution, three corrections are applied to the data: collection efficiency correction, aspiration efficiency correction and window correction. The efficiency correction accounts for the collection efficiency of the freerotating wing impactor. Experimental data of May and Clifford (1967) were parametrized, and the resulting correction function 
$c_{\mathrm{e}}$ is applied to each particle count:

$$
\begin{aligned}
& c_{\mathrm{e}}=\left(1.1889+\frac{-1.1889+0.014}{1+\left(\frac{1+\log (P)^{1.6369}}{0.7334}\right)}\right)^{-1}, \\
& P=\frac{\rho_{\mathrm{p}} v d_{\mathrm{p}}^{2}}{18 \eta l},
\end{aligned}
$$

with $\rho_{\mathrm{p}}$ particle density estimated from aerosol composition $\left(2.7 \mathrm{~g} \mathrm{~cm}^{-3}\right), v$ impaction speed, determined by wind speed and rotational speed, $d_{\mathrm{p}}$ particle diameter, $\eta$ viscosity of the air derived from actual temperature and $l$ characteristic dimension of the collection disc $(5 \mathrm{~cm})$. The efficiency correction becomes significant for particles smaller than $30 \mu \mathrm{m}$ in diameter. Particles smaller than $14 \mu \mathrm{m}$ were neglected, as for those, the efficiency correction exceeds 3 . The aspiration efficiency correction $c_{\mathrm{a}}$ of the single-stage impactor was calculated after Belyaev and Levin (1974):

$c_{\mathrm{a}}=\left(1+\left(\frac{v_{\mathrm{w}}}{v}\right)\left(1-\frac{1}{1+P \frac{v}{v_{\mathrm{w}}}}\right)\right)^{-1}$,

with $v_{\mathrm{w}}$ the wind speed, $v$ the speed in the aspiration nozzle. For the calculation of $P$ the characteristic dimension $l$ is taken as the nozzle diameter. The window correction accounts for particles touching the border of the analysis frame and thus being excluded from analysis. The effective area of analysis for those particles is smaller than the image frame, depending on the particle size. Therefore, each particle count was weighted by the function $c_{\mathrm{w}}$ :

$c_{\mathrm{w}}=\frac{w_{x} w_{y}}{\left(w_{x}-d_{\mathrm{p}}\right)\left(w_{y}-d_{\mathrm{p}}\right)}$

with $w_{x}$ and $w_{y}$ the dimensions of the analysis rectangle. After applying these corrections, the particles are classified into logarithmically equidistant size classes according to their volumeequivalent diameter. The errors in particle size of this method are assumed to be $5 \%$ for particles larger than $20 \mu \mathrm{m}$, and equal to $1 \mu \mathrm{m}$ for smaller ones. For the concentration, the uncertainty is estimated to follow a Poisson distribution $\left(n^{-0.5}\right.$, with $n$ the number of particles in each class) plus an additional $3 \%$ for the sampling volume uncertainty.

\subsection{Mineral identification and quantification}

Mineral identification of filter samples was performed using X-ray diffraction analysis (XRD) and the ICDD database (ICDD, 2002). Usually, clay minerals show no or only very weak reflections in randomly oriented powder samples if present in low amounts, due to their small particle size and their crystal structure (Moore and Reynolds, 1997), making identification rather difficult. Therefore, clay minerals were identified by additional preparation of textured specimens with preferred orientation of the platy particles. A comparison of signals from randomly oriented powder specimens and textured specimens of the same

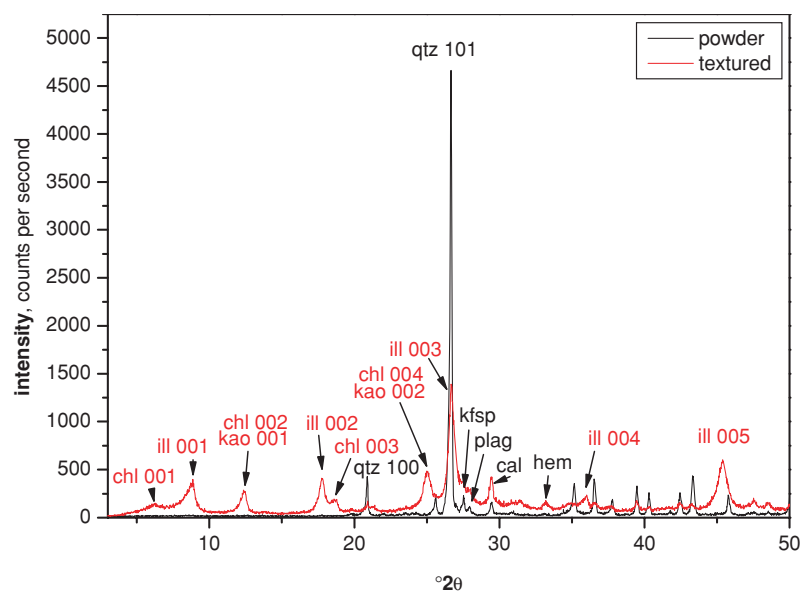

Fig. 4. X-ray spectra of randomly oriented powder and textured specimens for the dust storm sample of 24/25 May. In the powder sample, clay minerals show no or only weak reflections. These reflections become visible in textured samples, allowing mineral identification. In textured samples, minerals like quartz and feldspars (kfsp, plag) are present in lower amounts indicated by the lower intensity of main reflections (qtz, quartz; kfsp, potassium feldspar; plag, plagioclase; hem, hematite; cal, calcite; ill, illite; chl, chlorite; kao, kaolinite).

sample is shown in Fig. 4. The enhancement of the clay mineral signals can clearly be seen.

Relative mineral contents were then calculated using two different methods. (1) The standard-less reference intensity ratio (RIR) or 'matrix-flushing' method by Chung (1974) was used for filter samples where adding an internal standard was not possible. RIR values of most common mineral phases are already provided by the ICDD database. (2) The computer program FULLPAT published by Chipera and Bish (2002) was used for four filter samples collected during storm events. These four samples provided enough material that an internal standard could be added and distributed homogeneously within the specimens. To check the accuracy of the results, the four samples containing the internal standard were additionally quantified using the RIR method. Whereas the RIR method by Chung (1974) is a purely mathematical method using the intensities of the main reflections of the mineral phases present to calculate the mineral abundances, the FULLPAT method by Chipera and Bish (2002) is based on the assumption that in a mixture, XRD patterns for each individual phase can be added in the correct proportions to reproduce the observed diffraction pattern. Here, all individual XRD patterns - each representing one single mineral phaseare normalized to an internal corundum standard. By measuring all samples under the same conditions on the same instrument, all instrumental effects cancel out. In contrast, in the RIR method, only the identified minerals are summed up to $100 \%$. Further details of the two approaches can be found in Chung (1974) and Chipera and Bish (2002), quantification procedures 
for (clay) minerals in general are described in Moore and Reynolds (1997) and Brindley (1980).

For XRD measurements, the filter carriers containing the dust material were cut into $3 \mathrm{~cm} \times 3 \mathrm{~cm}$ pieces and mounted on a silicon wafer to reduce background effects. These specimens were then measured on a Seifert theta-theta instrument from $3^{\circ}$ to $70^{\circ} 2 \Theta$ with an increment of $0.02^{\circ}$ and a measuring time of $3 \mathrm{~s}$ for each step using $\mathrm{Cu} \mathrm{K}_{\alpha}$ radiation at $40 \mathrm{kV}$ and $30 \mathrm{~mA}$. It is assumed that, by keeping the dust material on the porous glass fibre filter pads, the particles show no preferred orientation or gradation which is required for the quantification procedures (Brindley, 1980; Moore and Reynolds, 1997). For preparation of textured samples after the first powder XRD measurement, the glass fibre filters were put into a flat polycarbonate vessel in which a few $\mathrm{mL}$ of distilled water was added. The sampled dust was separated from the filters using ultrasonic treatment. The suspension was then pipetted directly onto a silicon wafer and dried. The samples prepared this way were measured again under the same conditions. A preferred orientation of platy particles must be taken into account now (Fig. 4). Therefore, only a qualitative identification of the clay minerals can be obtained (Brindley, 1980; Moore and Reynolds, 1997). In addition, to check for the presence of smectite, ethylene glycol solution was added and the smectite 001 reflection was measured. Heating selected textured samples to 350 and $550^{\circ} \mathrm{C}$ allowed us to distinguish between chlorite and kaolinite. As an internal standard, $20 \mathrm{wt} \%$ corundum was added to the four storm event samples (12 May and 23 to 24 May) to allow quantification with FULLPAT. These samples were analysed using both techniques, FULLPAT and RIR, to directly compare the results of the two approaches. The total content of the 'clay fraction' (size fraction with particles smaller than $2 \mu \mathrm{m}$ ) was evaluated by separating it in a centrifuge and weighing the different fractions.

\subsection{Single particle chemistry and morphology}

Sampling for single particle analysis was performed by a miniature cascade impactor MINI (Kandler et al., 2007) and a Sigma2 sedimentation trap (VDI, 1997). Pure carbon adhesive and carbon-formvar-coated transmission electron microscopy grids (Plano TEM grids S-162 N3, Wetzlar, Germany) were used as sampling substrates. Particles smaller than $0.7 \mu \mathrm{m}$ in diameter were collected on TEM grids, larger particles on the carbon substrate. The small dimension of the MINI allows mounting it on a three-dimensional wind vane, which provides isoaxial collection of particles up to at least $30 \mu \mathrm{m}$ diameter. The samples were stored and transported under dry conditions (silica gel) to avoid later modification.

Approximately 74000 particles were analysed by scanning electron microscopy (FEI ESEM Quanta 200 FEG, Eindhoven, The Netherlands). Most of the samples were investigated under low vacuum conditions of $1 \mathrm{hPa}$ to minimize evaporation loss, a few samples were investigated under high vacuum conditions of $10^{-5} \mathrm{hPa}$. All samples were screened for distinctive features before automated particle analysis (software EDAX/AMETEK GENESIS 5.11) was performed. Appropriate magnifications were chosen for the different particle size regimes: $1.2 \mu \mathrm{m} \mathrm{pixel}^{-1}$ for particles larger than $20 \mu \mathrm{m}$ diameter, $280 \mathrm{~nm}_{\text {pixel }}{ }^{-1}$ for larger than $3 \mu \mathrm{m}, 140 \mathrm{~nm} \mathrm{pixel}^{-1}$ for larger than $2 \mu \mathrm{m}, 35 \mathrm{~nm} \mathrm{pixel}^{-1}$ for larger than $0.7 \mu \mathrm{m}$ and 17 and $4.2 \mathrm{~nm} \mathrm{pixel}^{-1}$ for smaller than $700 \mathrm{~nm}$ diameter. Automated particle analysis was performed on the carbon tape with the backscatter electron signal, and on TEM grids using the secondary electron signal. An acceleration voltage of $20 \mathrm{kV}$, 'spot size 4' and a working distance of approximately $10 \mathrm{~mm}$ was used for all automatically analysed samples.

The size of each individual particle is determined in the electron microscope by calculating a volume equivalent diameter as described above, assuming the particle height to be equal to the minor axis of the ellipse (Anderson et al., 1996). The chemical composition of the particles (all elements with $Z \geq 6$ ) was determined by energy-dispersive $\mathrm{X}$-ray microanalysis with a $\mathrm{Si}(\mathrm{Li})$ detector. X-ray count rates were corrected for matrix effects using the so-called 'standardless' procedures provided by the Ametek GENESIS software. For particles with diameters larger than $700 \mathrm{~nm}$, the classification of the particles into chemical classes was performed according to the scheme given by Kandler et al. (2007). As the signal to noise ratio is low for smaller particles, automatic analysis is not reliable. Thus, classification of these particles was carried out manually, taking into account the X-ray spectrum, morphological features and the characteristic alteration under electron bombardment.

To simplify the nomenclature, particle classes are named according to their most abundant component(s), which may include terms for mineral phases (e.g. gypsum, quartz). Those mineral phases were chosen as the most common components matching the measured elemental composition, but no true phase identification of individual particles was performed (e.g. by transmission electron microscopy/selected area electron diffraction).

To better visualize the variable composition of many particle classes, an element index is introduced. This index is defined as the atomic ratio of the concentration of the element considered and the sum of the concentrations of the elements $\mathrm{Na}, \mathrm{Mg}, \mathrm{Al}, \mathrm{Si}$, $\mathrm{P}, \mathrm{S}, \mathrm{Cl}, \mathrm{K}, \mathrm{Ca}, \mathrm{Ti}, \mathrm{Cr}, \mathrm{Mn}, \mathrm{Fe}$ and $\mathrm{Co}$. The concentration of $\mathrm{C}, \mathrm{O}$, $\mathrm{Cu}$ and $\mathrm{Ni}$ in the particles cannot be determined accurately due to a contribution of the sampling substrates. Therefore, these elements were not included in the calculation of the element index.

3.4.1. Calculation of the refractive index. To calculate the complex index of refraction from chemical data, the contribution of each component to the aerosol volume and the optical properties of all identified compounds are needed. As the optical properties are not available for some of the compounds, a simplified mineralogical composition has to be assumed. In this work, we use a five-component model consisting of 'average 
Table 1. Relative volume abundance of minerals deduced from single particle analysis as a function of the geometric mean diameter of the corresponding particle size interval

\begin{tabular}{lcccccccccc}
\hline Diameter $(\mu \mathrm{m})$ & 0.16 & 0.35 & 0.71 & 1.6 & 3.5 & 7.1 & 16 & 35 & 71 & 158 \\
\hline Hematite & 0.006 & 0.005 & 0.007 & 0.008 & 0.006 & 0.007 & 0.007 & 0.008 & 0.006 & 0.007 \\
Ilmenite & 0.001 & 0.001 & 0.002 & 0.001 & 0.000 & 0.000 & 0.001 & 0.000 & 0.001 & 0.000 \\
Rutile & 0.004 & 0.004 & 0.005 & 0.006 & 0.002 & 0.001 & 0.002 & 0.000 & 0.000 & 0.000 \\
Potassium feldspar & 0.145 & 0.153 & 0.207 & 0.220 & 0.232 & 0.237 & 0.235 & 0.231 & 0.182 & 0.145 \\
Plagioclase & 0.027 & 0.029 & 0.039 & 0.042 & 0.044 & 0.045 & 0.045 & 0.044 & 0.034 & 0.028 \\
Illite & 0.160 & 0.169 & 0.230 & 0.243 & 0.257 & 0.262 & 0.261 & 0.256 & 0.201 & 0.161 \\
Kaolinite & 0.031 & 0.033 & 0.045 & 0.047 & 0.050 & 0.051 & 0.051 & 0.050 & 0.039 & 0.031 \\
Chlorite & 0.027 & 0.029 & 0.039 & 0.042 & 0.044 & 0.045 & 0.045 & 0.044 & 0.034 & 0.028 \\
Quartz & 0.029 & 0.013 & 0.098 & 0.109 & 0.101 & 0.111 & 0.147 & 0.211 & 0.446 & 0.566 \\
Calcite & 0.014 & 0.016 & 0.069 & 0.081 & 0.091 & 0.092 & 0.059 & 0.036 & 0.012 & 0.003 \\
dolomite & 0.004 & 0.004 & 0.016 & 0.015 & 0.023 & 0.022 & 0.028 & 0.025 & 0.007 & 0.000 \\
Gypsum & 0.004 & 0.008 & 0.050 & 0.025 & 0.040 & 0.030 & 0.026 & 0.001 & 0.001 & 0.000 \\
Sodium chloride & 0.002 & 0.000 & 0.009 & 0.010 & 0.008 & 0.016 & 0.004 & 0.006 & 0.001 & 0.000 \\
Sulphates & 0.511 & 0.497 & 0.088 & 0.048 & 0.010 & 0.006 & 0.002 & 0.003 & 0.001 & 0.000 \\
Other & 0.035 & 0.039 & 0.097 & 0.105 & 0.093 & 0.076 & 0.088 & 0.085 & 0.034 & 0.031 \\
\hline
\end{tabular}

Table 2. Relative volume abundance of model substances derived from single particle analysis as function of geometric mean diameter of the corresponding size interval

\begin{tabular}{|c|c|c|c|c|c|c|c|c|c|c|}
\hline Diameter $(\mu \mathrm{m})$ & 0.16 & 0.35 & 0.71 & 1.6 & 3.5 & 7.1 & 16 & 35 & 71 & 158 \\
\hline 'Hematite' & 0.006 & 0.005 & 0.007 & 0.008 & 0.006 & 0.007 & 0.007 & 0.008 & 0.006 & 0.007 \\
\hline ‘Quartz' & 0.029 & 0.013 & 0.098 & 0.109 & 0.101 & 0.111 & 0.147 & 0.211 & 0.446 & 0.566 \\
\hline 'Average silicate' & 0.391 & 0.413 & 0.560 & 0.594 & 0.626 & 0.640 & 0.636 & 0.624 & 0.491 & 0.393 \\
\hline 'Calcite' & 0.018 & 0.020 & 0.085 & 0.096 & 0.114 & 0.114 & 0.087 & 0.062 & 0.019 & 0.003 \\
\hline 'Sulphate' & 0.515 & 0.505 & 0.138 & 0.073 & 0.050 & 0.036 & 0.027 & 0.004 & 0.002 & 0.000 \\
\hline 'Other' & 0.041 & 0.044 & 0.112 & 0.121 & 0.102 & 0.093 & 0.096 & 0.091 & 0.036 & 0.031 \\
\hline
\end{tabular}

silicate', quartz, calcite, hematite and ammonium sulphate. The chemical composition of the average silicate component is deduced from the bulk mineralogical measurements by assuming average chemical compositions for the identified mineral phases (Hillier and Velde, 1991; Barthelmy, 2007). The simplest method of calculating the volume composition would be to assign the corresponding pure component to each particle class identified by single particle analysis. However, optical properties in the visible wavelengths are very sensitive to the volume fraction of iron oxides but not to iron incorporated into the crystal structure of silicates (Karickhoff and Bailey, 1973). In addition, iron oxide is present in more particle classes than the iron-rich class. As a result, this simple method is not accurate enough. Therefore, the hematite volume content is derived from the total iron content of the individual particles of each class containing substantial amounts of iron. So, the total iron content of all particles in the mineral dust classes, except the calcium-dominated ones, is calculated. Afterwards, $20 \%$ of this value are assumed to be hematite, which is an average compiled from literature (Eissa et al., 1988; Eyre and Dickson, 1995; Murayed et al., 2000; Lafon et al., 2004; Lafon et al., 2006). Table 1 gives the daily average of the size-resolved volume composition at Tinfou ground station. These data are simplified to the five-component mineralogical model (Table 2). For better distinction, model substance names are set in single quotes. The complex refractive index is calculated as a function of particle size and wavelength by applying a simple volume mixture rule (see also Petzold et al., 2008) to optical material properties taken from the literature (Ivlev and Popova, 1972; Philipp, 1985; Tropf, 1998; Sokolik and Toon, 1999) and laboratory measurements (Müller et al., 2008). Table 3 shows the refractive index values of the model substances. For the 'other' model substance, a wavelength-independent refractive index of 1.5 is assumed, which is estimated from Dubovik et al. (2002).

\section{Results and discussion}

\subsection{Mass concentrations}

During the course of the measuring period, daily mass concentrations were extremely variable. Fig. 5 shows the time series of concentrations on 12-hour basis for TSP, $\mathrm{PM}_{10}$ and $\mathrm{PM}_{2.5}$ 
Table 3. Complex refractive indices of the model substances

\begin{tabular}{lccccccc}
\hline Wavelength (nm) & 350 & 450 & 630 & 670 & 870 & 1020 & 1640 \\
\hline 'Hematite' & $2.3-1.032 \mathrm{i}$ & $2.5-1.01 \mathrm{i}$ & $2.8-0.54 \mathrm{i}$ & $2.7-0.05 \mathrm{i}$ & $2.6-0.026 \mathrm{i}$ & $2.4-0.018 \mathrm{i}$ & $2.4-0.024 \mathrm{i}$ \\
'Quartz' & 1.57 & 1.55 & 1.55 & 1.54 & 1.53 & 1.53 & 1.53 \\
'Average silicate' & 1.595 & 1.57 & 1.56 & 1.55 & 1.542 & 1.54 & 1.538 \\
'Calcite' & 1.69 & 1.67 & 1.66 & 1.65 & 1.65 & 1.64 & 1.63 \\
'Sulphate' & 1.54 & 1.54 & 1.53 & 1.52 & 1.52 & 1.51 & $1.49-10^{-4} \mathrm{i}$ \\
'Rutile' & $3.9-0.4 \mathrm{i}$ & $3.02-0.06 \mathrm{i}$ & 2.9 & 2.84 & 2.78 & 2.75 & 1.5 \\
'Other' & 1.5 & 1.5 & 1.5 & 1.5 & 1.5 & & 1.5 \\
\hline
\end{tabular}

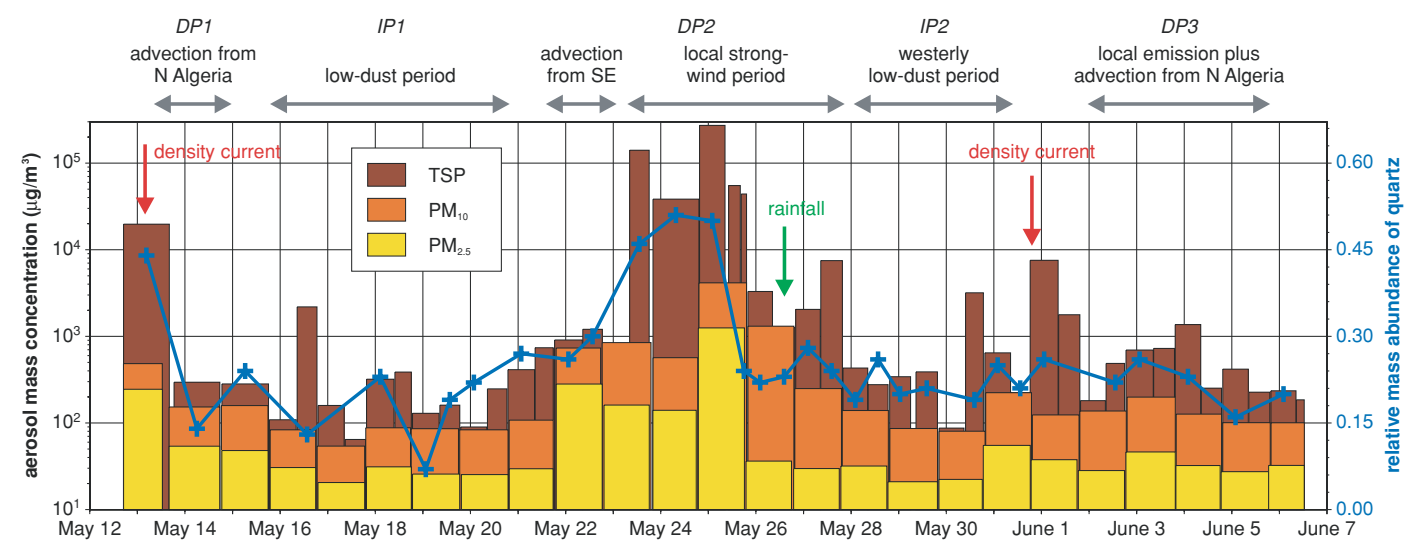

Fig. 5. Time series of mass concentrations measured at Tinfou, Morocco. In addition, the relative abundance of quartz is shown as crosses. In the top row, prevailing advection situations are given. Individual meteorological events are marked.

for the whole experimental period. Based on detailed air mass backtrajectory calculations (Knippertz et al., 2008), different air mass regimes within the Sahara and the surrounding areas were found. Various concentration levels ranging from desert background up to dust wind conditions can be distinguished. For background atmospheric conditions, mass concentrations of approximately $100 \mu \mathrm{g} \mathrm{m}^{-3}$ for TSP, $80 \mu \mathrm{g} \mathrm{m}^{-3}$ for ' $\mathrm{PM}_{10}$ ' and $30 \mu \mathrm{g} \mathrm{m}^{-3}$ for the ' $\mathrm{PM}_{2.5}$ ' were determined. During haze periods and density current-induced dust fronts (red arrows in Fig. 5) all concentration levels are increased by approximately one order of magnitude. During moderate dust winds, concentrations up to $300000 \mu \mathrm{g} \mathrm{m}^{-3}$ (TSP), $3000 \mu \mathrm{g} \mathrm{m}^{-3}\left(\mathrm{PM}_{10}\right)$ and $1000 \mu \mathrm{g} \mathrm{m}^{-3}$ $\left(\mathrm{PM}_{2.5}\right)$ were encountered.

There is an obvious correlation between dust concentrations and the local wind speed. Of the three measured mass concentrations, the TSP correlates best with the local wind speed (Fig. 6). Under high dust concentrations, particles with diameters of more than $10 \mu \mathrm{m}$ account for more than $90 \%$ of the total airborne aerosol mass. The size distributions discussed in the next paragraph support this finding.

The $\mathrm{PM}_{10}$ and especially the $\mathrm{PM}_{2.5}$ mass concentrations show a poor correlation with the local wind speed. This indicates mainly local production of the particles larger than $10 \mu \mathrm{m}$ diameter, and significant contribution of advection to the concentration of the smaller ones. The concentrations of $\mathrm{PM}_{10}$ and $\mathrm{PM}_{2.5}$

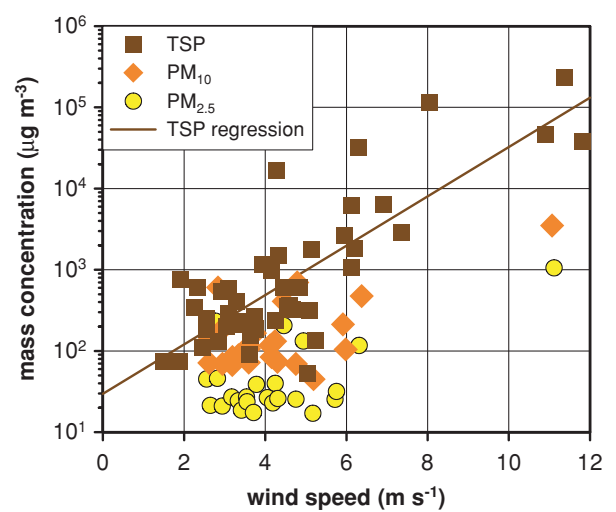

Fig. 6. Total suspended particles (TSP), $\mathrm{PM}_{10}$ and $\mathrm{PM}_{2.5}$ mass concentrations versus wind speed at Tinfou, Morocco. The TSP values can be expressed as TSP $=29.66 \exp (0.7 u)$, with $T S P$ in $\mu \mathrm{g} \mathrm{m}^{-3}$ and the wind speed $u$ in $\mathrm{m} \mathrm{s}^{-1}$.

fractions, which can be addressed as the long-range transport fractions of the atmospheric aerosol (e.g. Schütz and Sebert, 1987; Reid et al., 2003), are determined to a major extent by regional-scale emission and transport processes. The ordinate intersect of the regression line in Fig. 6 at zero wind speed can be interpreted as background concentration for TSP over the desert. At Tinfou, this value is on the order of $30 \mu \mathrm{g} \mathrm{m}^{-3}$. In 
a previous compilation (Jaenicke, 1988) of TSP concentrations versus wind speed from different areas in the Sahara and other desert sites of Israel and the former USSR a concentration of $50 \mu \mathrm{g} \mathrm{m}^{-3}$ was determined for zero wind speed. This might be an indication for a common phenomenon and supports the hypothesis that over desert regions a reservoir of dust-laden air masses is constantly available for transport into the surrounding areas, as well as for long-range transport.

\subsection{Size distributions}

The size distribution of the atmospheric aerosol and its spatial distribution are key parameters for any numerical simulations of radiative effects of mineral dust in the atmosphere (Sokolik et al., 2001). Thus, special attention has been paid during this project to measurements of the total size distribution in the boundary layer and at higher altitudes on board of the research aircraft Falcon (Weinzierl et al., 2008). Compared with other atmospheric aerosols, desert aerosol shows size distributions over an extreme wide range from nanometer sizes up to hundreds of micrometers in diameter, when dust storms are encountered (Schütz, 1989). Thus, measurements have to be carried out well beyond the usual $\mathrm{PM}_{10}$ cut-off size.

Average size distributions at Tinfou ground stationclassified according to the meteorological situations-are plot-

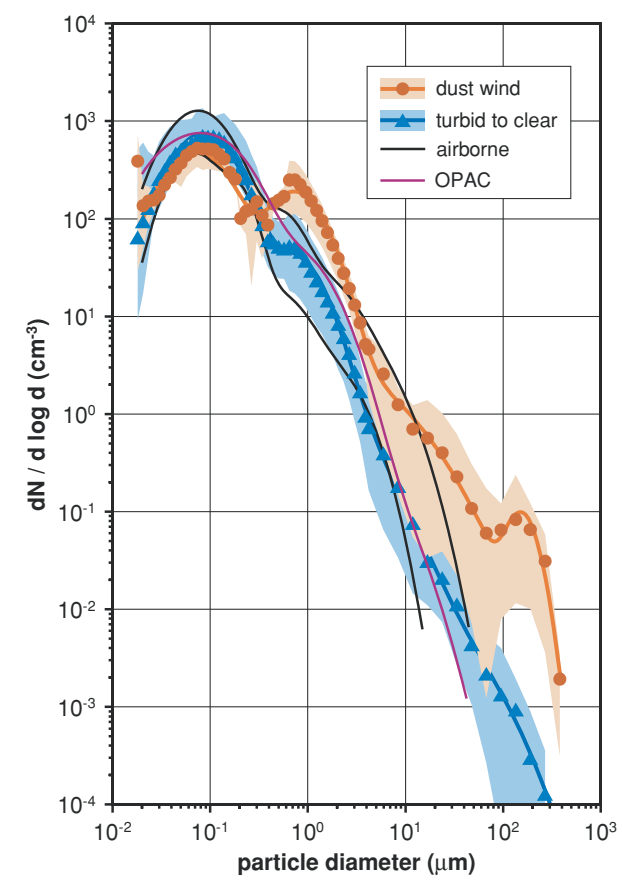

Fig. 7. Boundary layer aerosol size distributions at Tinfou, Morocco, range of airborne measurements by the Falcon aircraft and the OPAC model approximation 'desert' plus ' $500 \mathrm{~cm}^{-3}$ of water-soluble particles' (Hess et al., 1998). Lines are parametrization curves, the shaded areas show the variability between maximum and minimum values. ted in Fig. 7 together with the range of aircraft measurements on board of the Falcon at altitudes of about $500 \mathrm{~m}$ above Tinfou, still within the boundary layer. The ground-based measurements show a large variability. Two major regimes of the size spectrum can be distinguished. For particles smaller than $500 \mathrm{~nm}$ diameter, the distributions show maxima around $80 \mathrm{~nm}$, largely unaffected by variations in meteorological and dust emission conditions. This range probably reflects a background of anthropogenic influences from near or distant sources. However, for particles larger than $500 \mathrm{~nm}$, the variation amounts to more than one order of magnitude, most probably due to local and regional mineral dust emissions. A second mode is observed around $600 \mathrm{~nm}$. For particles larger than $10 \mu \mathrm{m}$ diameter, concentration variations of approximately three orders of magnitude were found. Under heavy wind conditions, the threshold wind speed is exceeded and saltation-sand blasting (Tsoar and Pye, 1987; Marticorena and Bergametti, 1995) can be observed visually. The mode in the size distribution at $d_{\mathrm{p}} \approx 150 \mu \mathrm{m}$ may be explained by the ('Bagnold') minimum in the grain size versus friction velocity relation (Iversen and White, 1982; Cornelis and Gabriels, 2004) in conjunction with the soil size distribution. Occurrence of an 'ultra-giant' particle mode for desert dust has been also reported for other locations (Mikami et al., 2005; O'Hara et al., 2006; Mikami et al., 2007).

For particles with $d_{\mathrm{p}}<30 \mu \mathrm{m}$, the size distributions measured on board of the Falcon aircraft (Weinzierl et al., 2008) at altitudes of about $500 \mathrm{~m}$ above Tinfou follow a pattern similar to the ground-based measurements. This indicates that the boundary layer is rather well mixed. It is not surprising that the size distribution cannot be followed on the aircraft to sizes much beyond $30 \mu \mathrm{m}$ particle diameter. The counting statistics of the spectrometer and the aspiration efficiency of the probe (Weinzierl et al., 2008) can explain that only few of the largest particles penetrate into the sizing volume. Moreover, the high aircraft travelling speed does not allow averaging over a suitable sampling time to achieve better counting statistics.

As the shape of ground-based and airborne size distributions is quite similar, they can be approximated by the same four log-normal distribution functions independent of atmospheric conditions. As an example, the OPAC mineral dust approximation (Hess et al., 1998) is also plotted in Fig. 7, and it becomes obvious that this model distribution is suitable for describing the desert background aerosol. For situations with higher local dust concentrations, however, new parametrizations have to be calculated. Table 4 gives the parameters of log-normal distributions deduced from the measurements in this work for background and high-dust conditions. Aerosol size distribution as a function of the particle diameter $d_{\mathrm{p}}$ can be calculated as

$\frac{\mathrm{d} n}{\mathrm{~d} \log d_{\mathrm{p}}}=\frac{\ln 10}{\sqrt{2 \pi}} \sum_{i=1}^{4} \frac{n_{i}}{\ln \zeta} \exp \left(-\frac{\ln ^{2}\left(d_{\mathrm{p}} \cdot m_{i}^{-1}\right)}{2 \ln ^{2} \zeta_{i}}\right)$

with $n_{i}, m_{i}, \zeta_{i}$ parameters of the log-normal distributions. 
Table 4. Parameters of log-normal distributions fitting the size distributions measured at Tinfou for high dust and medium to low dust conditions

\begin{tabular}{lccccc}
\hline & & $i=1$ & $i=2$ & $i=3$ & $i=4$ \\
\hline High dust & $n_{i}$ & 367.8 & 117.9 & 3.839 & 0.03189 \\
& $m_{i}$ & 0.07061 & 0.7443 & 1.732 & 153.9 \\
& $\zeta_{i}$ & 2.020 & 1.791 & 3.718 & 1.381 \\
Medium to low dust & $n_{i}$ & 497.1 & 72.33 & 20.64 & 0.002031 \\
& $m_{i}$ & 0.08542 & 0.03529 & 0.7342 & 31.08 \\
& $\zeta_{i}$ & 1.898 & 5.208 & 1.749 & 2.486 \\
\hline
\end{tabular}

To verify the numerical simulations of the radiative transfer, our closure experiment requires measurements representing the actual size distribution over the whole column for the same time period in which the airborne radiation measurements were performed. In general, data on measured size distributions over large deserts are poor. Size distributions as a function of altitude are unknown to the authors. Columnar averaged size distributions can be derived from AErosol RObotic NETwork (Dubovik et al., 2006) spectral aerosol optical depth inversion products originating from a few desert sites. Desert aerosol size distributions measured near the surface can be found in the literature representing different locations, seasons and dust emission conditions. Fig. 8 gives examples of frequently cited size distributions for desert background, dust wind and sandstorm conditions for several measurement locations, together with a size distribution for the average high-dust condition at Tinfou, Morocco. This compilation confirms that the size distributions of dust wind situations exhibit a large variability. Therefore, it is not possible to use any of the previously published general model distributions for model calculations in the SAMUM campaign. Instead, the actual size distribution has to be used for each meteorological situation.

\subsection{Composition}

4.3.1. Bulk mineralogy. All samples are composed of the same minerals in varying quantities: quartz, potassium feldspar, plagioclase, calcite, hematite and the clay minerals chlorite, kaolinite and illite. Due to the high concentration of well crystalline quartz, the storm samples showed only weak reflections of clay minerals, leading to difficulties in quantifying the concentrations of the latter minerals. In contrast, the clay mineral contents in the other filter samples was high enough to enable their quantification. The RIR method yielded the following absolute amounts: $27 \%$ illite, $4 \%$ kaolinite and $3 \%$ chlorite. The relationship of illite : kaolinite : chlorite of approximately $9: 1$ : 1 was then used to calculate relative proportions of clay minerals present in the samples. This relationship is very similar to findings at Cape Verde (Glaccum and Prospero, 1980) and over Israel (Falkovich et al., 2001). Slightly lower illite dominance

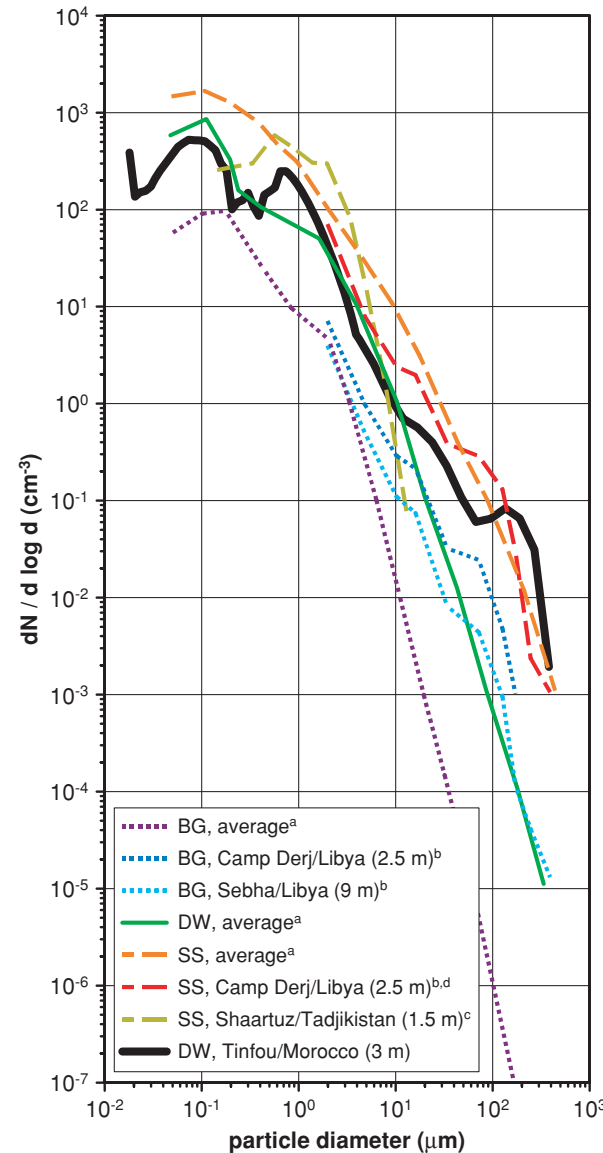

Fig. 8. Desert aerosol size distributions. BG, background conditions; DW, dust wind; SS, sand storm. Distances in parentheses are measurement altitudes above ground. (a) Averages for meteorological conditions classified by d'Almeida (1987) from measurements at Matam/Senegal, Tombouctou/Mali and Agadez/Niger (d'Almeida and Schütz, 1983); (b) Schütz and Jaenicke (1974); (c) Gillette and Nagamoto (1993); (d) later parametrized by Jaenicke $(1983 ; 1988)$ as 'desert duststorm', but occasionally also cited as Shettle (1984).

is reported for Northern Algeria (Goudie and Middleton, 2001), for Saharan dust over Sardinia (Guerzoni et al., 1997) as well as over north eastern Spain (Avila et al., 1997) and over the North Atlantic Ocean, west of the African coast (Chester and Johnson, 1971; Chester et al., 1971; Chester et al., 1972). In contrast, for Mali a kaolinite dominance was measured (Kiefert et al., 1996). The total content of clay minerals measured by gravimetrical methods was found to range between $15 \%$ and $20 \%$. These values were normalized to $100 \%$ clay content and divided into the three mineral phases, using the relationship above.

The relative mineral contents (mean value of the four powder samples) measured by the two different X-ray diffraction techniques are compared in Fig. 9. Clay minerals are plotted in dashed lines due to the above stated assumptions made here. Both methods yield similar results for the relative mineral 


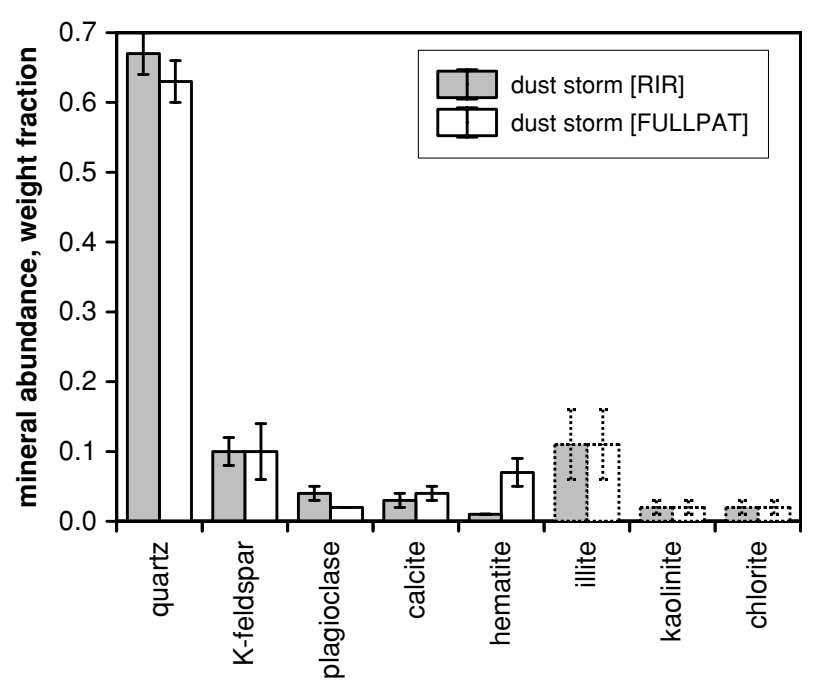

Fig. 9. Comparison of the RIR and FullPat methods for the four storm samples. Clay minerals are shown in dashed lines due to the fact that their relative mineral content was calculated from a total clay content of $15 \%$. The relative mineral proportions were corrected for $20 \%$ of corundum internal standard. Error bars represent the standard deviation of the mean of the four samples except for clay minerals, where empirical errors are given.

abundances, except for hematite with $7 \mathrm{wt} \%$ obtained from FULLPAT and $1 \mathrm{wt} \%$ from the RIR method.

Only $30 \%$ of all measured filter samples yielded appropriate XRD intensities to enable a quantitative phase determination using the RIR method by Chung (1974). Due to the weak reflections of clay minerals in powder samples, their identification is ambiguous. Clay minerals were identified using textured samples of the 'clay fraction' samples, yielding much higher intensities. All samples showed the same qualitative mineral composition of quartz, potassium feldspar, plagioclase, calcite, hematite and the clay minerals illite, kaolinite and chlorite. The relative mineral contents did not differ significantly and could not be correlated with specific events. Therefore, the mean quantitative composition was calculated and the results were compared with the results of the samples from the storm event. Fig. 10 shows the comparison of the high-dust and low-dust sample types. The two sample types differ significantly. The storm event provided much more quartz and more calcite and illite but less potassium feldspar. No or only small differences were found for plagioclase, hematite and the clay minerals kaolinite and chlorite.

During the dust storm events, quartz is the predominant mineral phase. Quartz usually doesn't show preferred cleavage, leading to a high mechanical stability. In contrast, feldspars and calcite are mechanically less stable and can be grounded easily by transport. Clay minerals are usually much smaller and also mechanically weak. So, quartz is present in very large amounts only if enough energy for the transport is available. It becomes

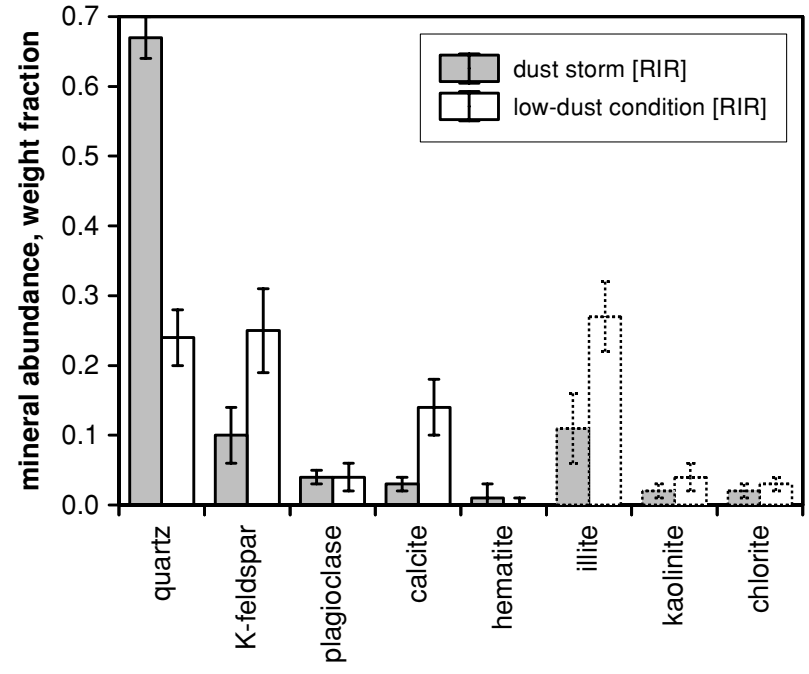

Fig. 10. Average relative composition of the dust storm and low-dust condition samples. Error bars represent the standard deviation of the mean relative mineral contents.

apparent that wind energy is the controlling factor for the separation and transport of different mineral groups on this local scale.

4.3.2.1. Chemical composition. The element-chemical composition was determined by electron microscopy and energydispersive X-ray analysis for approximately 74000 particles, of which 45000 were collected at Tinfou ground station, 12000 onboard the Falcon aircraft and 17000 onboard the Partenavia. Sample images of Saharan aerosol particles are given elsewhere (Kandler et al., 2007; Weinzierl et al., 2008; Wiegner et al., 2008).

The time-averaged composition of the aerosol at Tinfou ground station is shown in Fig. 11. Relative abundances are given in terms of particle classes. All silicates except quartz are sorted into the silicates class, as the different silicate minerals cannot be distinguished from each other reliably by the elemental composition only. If no separate class of ammonium sulphate is displayed (see below), the sulphates class holds all kinds of sulphate particles except gypsum.

From the chemical point of view, three size regimes can be identified $\left(d_{\mathrm{p}}<500 \mathrm{~nm}, 500 \leq d_{\mathrm{p}}<50 \mu \mathrm{m}, d_{\mathrm{p}} \geq 50 \mu \mathrm{m}\right)$. For smaller than $500 \mathrm{~nm}$ diameter, the aerosol is in average composed of sulphates and mineral dust in equal amounts. At $500 \mathrm{~nm}$, there is an abrupt change in the aerosol chemical composition, which is also identified by other methods of measurement (Kaaden et al., 2008; Müller et al., 2008). Such a change is also reported over the Asian continent (e.g. Iwasaka et al., 2003) and may be a common feature of desert aerosol. Mineral dust is dominating the composition for particles with diameter larger than $500 \mathrm{~nm}$; the sulphates only contribute less than $10 \%$. For larger 


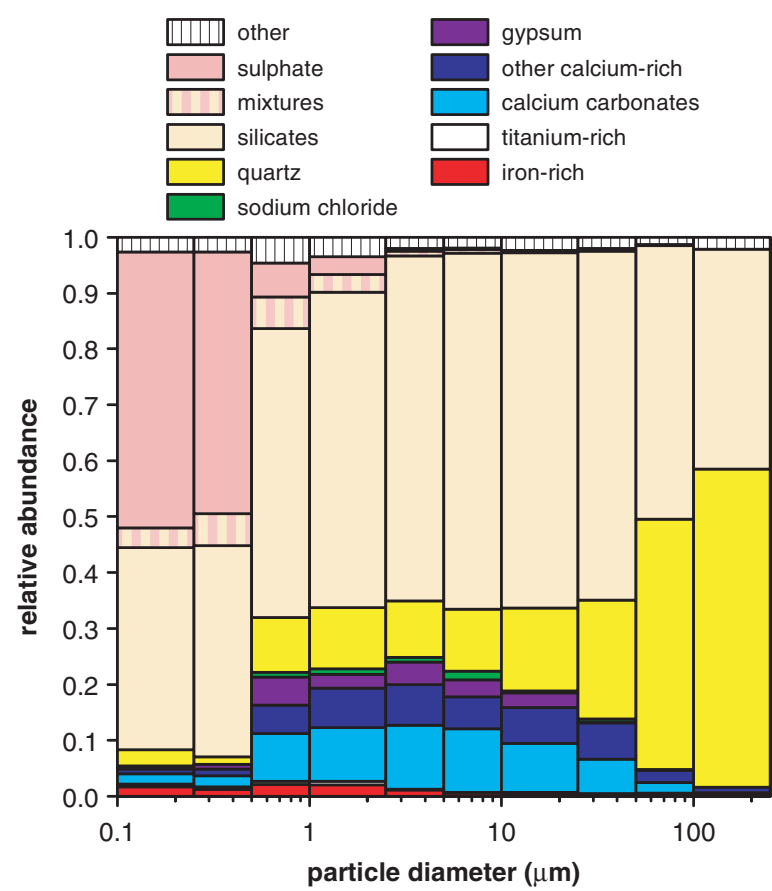

Fig. 11. Average relative volume abundance of the different particle classes at Tinfou ground station.

than $2.5 \mu \mathrm{m}$ particle diameter, mineral dust is virtually the only component. Between $500 \mathrm{~nm}$ and $50 \mu \mathrm{m}$ diameter, silicates are the major component of the mineral dust. To a lesser extent quartz and calcium-rich particles (carbonates like calcite and dolomite as well as gypsum and apatite) contribute to the composition. The calcium-rich particles appear as a log-normal mode in the mineral dust centered around $3 \mu \mathrm{m}$ particle diameter. Sodium chloride, iron-rich (like hematite) and titanium-rich material (rutile and ilmenite or titano-magnetite) are found in small quantities. In traces, 20 minerals (including ones containing the elements $\mathrm{Sr}, \mathrm{Zr}, \mathrm{Nb}, \mathrm{Ba}, \mathrm{La}, \mathrm{Ce}, \mathrm{Pb}, \mathrm{Bi}$ ) were found, but neglected due to their very rare occurrence. Finally, for larger than $50 \mu \mathrm{m}$ in diameter, quartz becomes a major component, reflecting the higher durability of quartz grains to mechanical abrasion compared with the other materials.

To illustrate the temporal variability, Fig. 12 shows the chemical composition for the most silicate-rich and the most calcium-rich day. Between these two extremes, the amount of calcium-dominated particles in the range between 1 and $25 \mu \mathrm{m}$ diameter varies approximately from $10 \%$ to $25 \%$. Meteorological observations suggest (Knippertz et al., 2008) that these findings are caused by an addition of calcium-rich material to a silicate 'background', as for 3 June, strong advection from a prominent dust source (Chott El Djerid and surroundings; see also Desboeufs and Cautenet, 2005; O'Hara et al., 2006) occurred.

For single days, it was possible to distinguish several kinds of sulphates by the single particle analysis. As an example, Fig. 13 gives a more detailed view of the typical sulphate composition. Again, we find a sudden transition around $500 \mathrm{~nm}$ in particle diameter. Smaller particles are dominated by ammonium sulphate (identified by their typical morphology and the presence of sulphur and nitrogen X-ray peaks), which is confirmed by in situ measurements (Kaaden et al., 2008). For larger particles, any mixtures of sodium-magnesium-potassium-calcium sulphates are observed. The latter ones may be deflated from dry lakes in the desert, whereas the former ones most likely originate from the gas phase.

Taking a closer look into the most abundant class, the silicates, Fig. 14 reveals that the mineralogical composition within this class depends on particle size. Larger than $2.5 \mu \mathrm{m}$ particle diameter, the $\mathrm{Al} / \mathrm{Si}$ as well as the $\mathrm{Mg} / \mathrm{Si}$ ratios start to
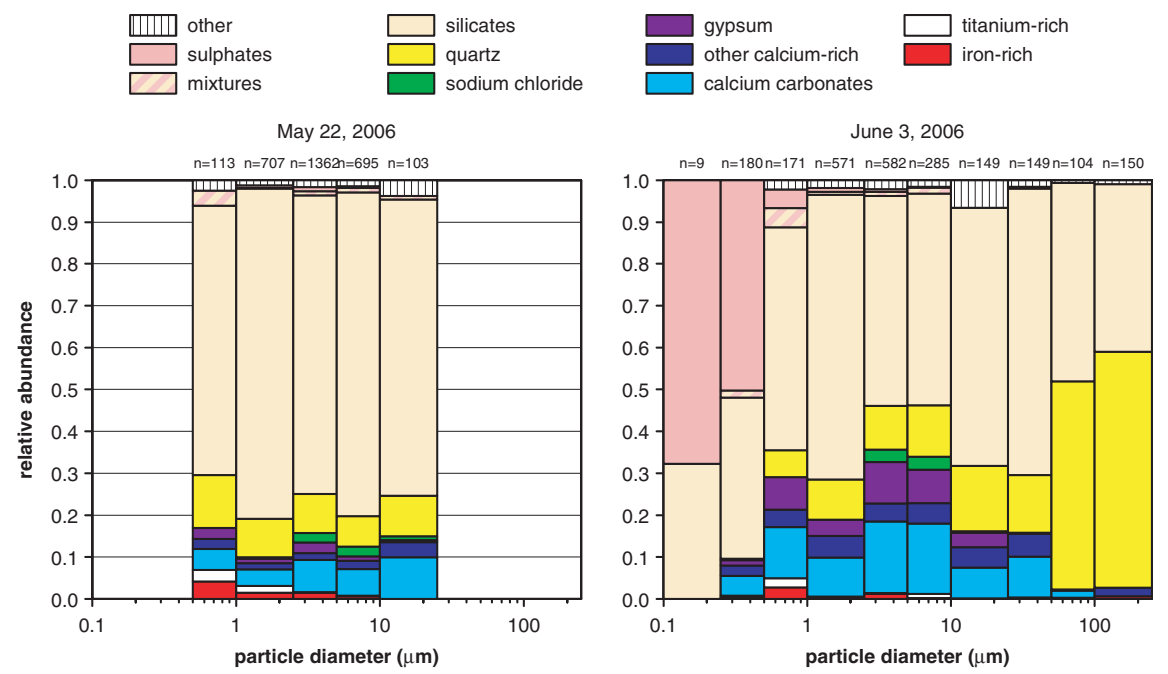

Fig. 12. Size distribution of the relative abundance of particle classes for 22 May and 3 June 2006. The total number of analysed particles $n$ is given for each size class. 


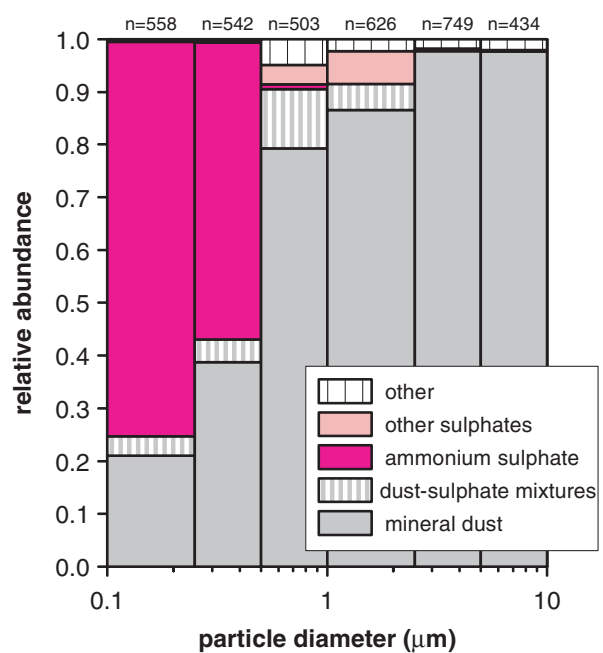

Fig. 13. Typical example of the size-resolved abundance of the various sulphate classes and mineral dust particles (31 May 2006).

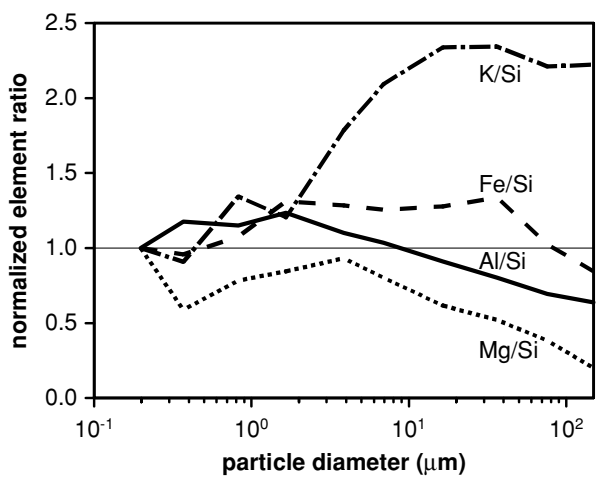

Fig. 14. Size dependence of normalized element ratios for the class of silicate particles at Tinfou ground station.

decrease with increasing particle size, whereas in the same range, the $\mathrm{K} / \mathrm{Si}$ ratio strongly increases. Interestingly, the $\mathrm{Fe} / \mathrm{Si}$ ratio shows elevated values between 2.5 and $50 \mu \mathrm{m}$ but almost no size dependence in this region. However, there exist too many silicates with very similar chemical compositions to allow phase determination with the methods used in this work.

A scatter plot of iron index versus silicon index for the silicate, quartz and iron-rich classes at Tinfou is shown in Fig. 15. Particle size is given as colour. The silicate and quartz classes appear as separate clusters. Whereas there is a clear partition in terms of particle size for the quartz cluster showing higher iron indices for larger particles, only a weak increase of the silicon index with particle size is visible in the silicates class. The latter effect can be explained by the observed sulphate coatings of the silicate particles, which contributes stronger to particle volume for small particles. This is confirmed by the increase of the sulphur index for decreasing particle sizes. Assuming an average silicate composition core and an ammonium sulphate coating, a median thickness of $20 \mathrm{~nm}$ can be calculated for these particles (for details on calculation, see Kandler et al., 2007).
To understand the increase of iron index with increasing particle size for the quartz class, one has to consider the generation of the X-ray radiation from which the chemical composition is derived. For large grains, the EDX information comes only from the upper few micrometres and compounds concentrated near the surface will be overrepresented in the resulting element index. Therefore, it can be concluded that the quartz grains significantly larger than $10 \mu \mathrm{m}$ have iron oxide coatings. This conclusion was strengthened by observations in the light microscope (Fig. 16). The large transparent quartz grains tended to have reddish brown blotched coatings, probably hematite, whereas slightly transparent grains seemed to be rather homogeneous. Thus, it is concluded that separate particle types with different location of iron-rich material within the particle exist. In some particles, iron is enriched at the surface, others have the iron distributed throughout their volume and most probably intermediate states also occur. A similar pattern of iron distribution can be found in desert aerosol from Israel (Falkovich et al., 2001), though it is not explicitly stated by the authors.

While there is a strong dependence of the chemical composition on particle size, the temporal variation of the major compounds seems to be rather small. Fig. 17 shows a time-series for particles between 2.5 and $10 \mu \mathrm{m}$ in diameter. For this size range, the silicates class is always dominating, followed by quartz and the calcium-dominated particle classes as described above. As already seen in Fig. 12, the data of 3 June show a slight increase in the concentration of the calcium-dominated particles, especially for the gypsum class. In contrast, on 22 and 27 May, the abundance of the calcium-dominated particles is low and the silicate content is increased. On 3 June, more information on the chemical composition in the vertical column is available by aircraft measurements. Fig. 18 displays the chemical composition of particles between 1 and $2.5 \mu \mathrm{m}$ in diameter, for four levels of altitude. In contrast to most other days, a strong stratification is visible (see also Petzold et al., 2008). The transport situation with calcium-rich material being advected from southern Tunisia and eastern Algeria is clearly reflected in the chemical composition measured at 0.3 and $1.5 \mathrm{~km}$ above ground. At $3.2 \mathrm{~km}$ altitude, this enrichment of the calcium-dominated particles cannot be seen, which is in accordance with the meteorological situation (Knippertz et al., 2008).

4.3.2.2. Morphology. The geometrical shape of individual mineral dust particles is expressed as the aspect ratio in the present contribution. The aspect ratio of the particles depends on their chemical composition. Most of the mineral dust constituents - the silicates and carbonates, the mixtures as well as the iron- and titanium-rich particles-have a very similar median aspect ratio of about 1.6. Sodium chloride particles have a median aspect ratio of 1.48 , ammonium sulphate particles of 1.31. This reflects the cubic shape in the former and the oval shape in the latter case. The only major component showing a higher value is gypsum (1.71), due to the needle-like 


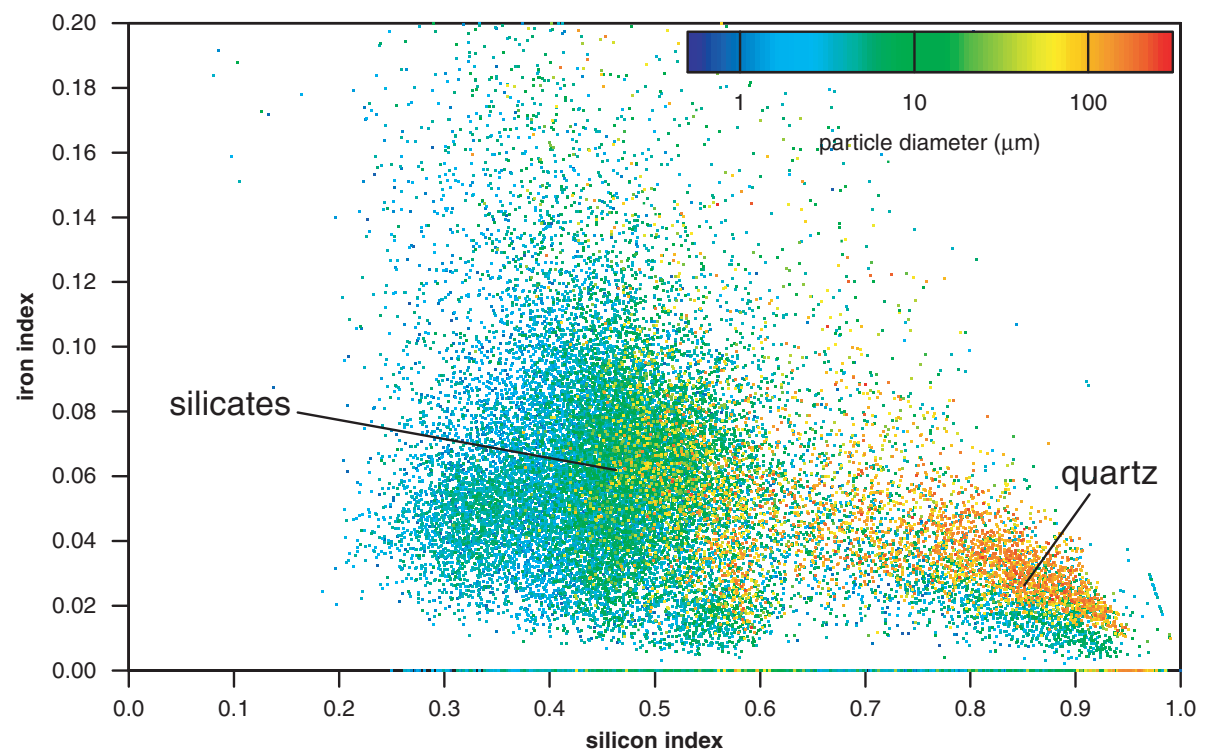

Fig. 15. Iron index versus silicon index for all silicon-dominated particles larger than $700 \mathrm{~nm}$ in diameter at Tinfou. Particle size is shown colour-coded.

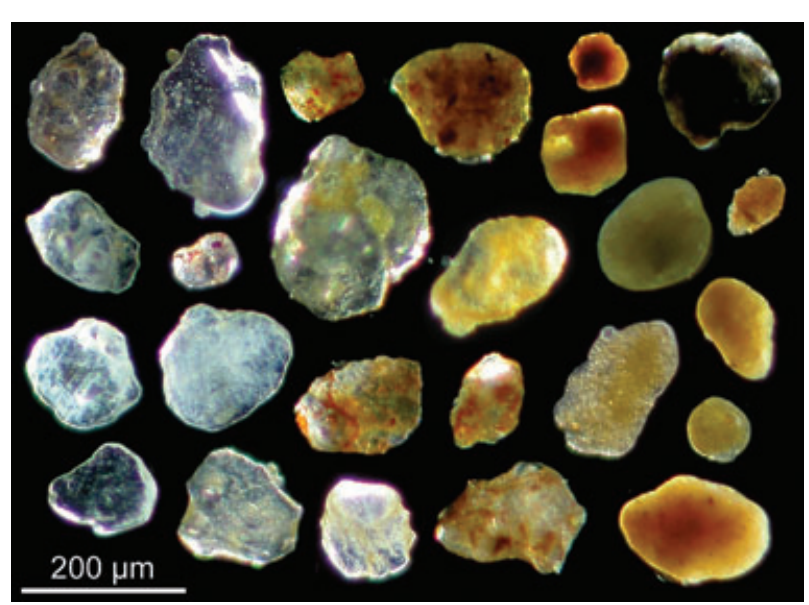

Fig. 16. Selected large particles showing airborne mineral dust with different types of (most probably iron-derived) colouring. Left-hand panel: particles are virtually free of reddish colouring. Central panel: the colouring material is present as irregular spots, on the surface or within the particle. Right-hand panel: colour is distributed homogeneously in the particle.

shape of a fraction of the gypsum group. Except for the sulphates, these findings are in good agreement with measurements of transported Saharan dust at Tenerife (Kandler et al., 2007). For the sulphates, it is necessary to distinguish between ammonium sulphate-which was not investigated at Tenerife - and the other sulphates class (sodium-magnesium-potassium-calciummixed sulphates), the latter ones having a higher aspect ratio of 1.5. The even higher aspect ratios of the 'other sulphates' class found at Tenerife must be explained by their advanced aging (recrystallization of solute droplets).
The density distribution of the particle aspect ratio $h(A R)$ can be parametrized very accurately by a modified log-normal distribution (Kandler et al., 2007):

$h(A R)=\frac{1}{\sqrt{2 \pi \sigma(A R-1)}} \exp \left(-\frac{1}{2}\left(\frac{\ln (A R-1-\mu)}{\sigma}\right)^{2}\right)$,

with the parameters $\sigma$ and $\mu$, which are given in Table 5 for each particle class and all particles measured at Tinfou.

The size dependence of the aspect ratio shown in Fig. 19 reflects its dependence on the chemical particle class and, thus, the size distribution of these classes. For larger than $500 \mathrm{~nm}$ particle diameter, the median aspect ratio is rather constant, with values of about 1.6. Towards smaller particles, it decreases to about 1.3. As it is to be expected from the low temporal variability of the chemical composition, the temporal variability of the aspect ratio is also low. Even the aspect ratio density distribution-expressed by the inter quantile range in Fig. 19does not change overly with the mineral dust composition.

4.3.2.3. Complex index of refraction. The dependence of the aerosol refractive index on particle size and wavelength is shown in Fig. 20. The most obvious change of the real part at $500 \mathrm{~nm}$ diameter is caused by the composition change from an ammonium sulphate-containing aerosol to pure mineral dust. Additionally, a weak increase in the real part can be seen between 1 and $10 \mu \mathrm{m}$ diameter, which is caused by the higher contribution of calciumdominated particles in this size range. For the imaginary part, the same transition at $500 \mathrm{~nm}$ particle size is observed. In addition, a weak relative maximum is observed between 10 and $100 \mu \mathrm{m}$ particle diameter, which is caused by an increase in the relative iron content of the silicates class. Mean values of the 


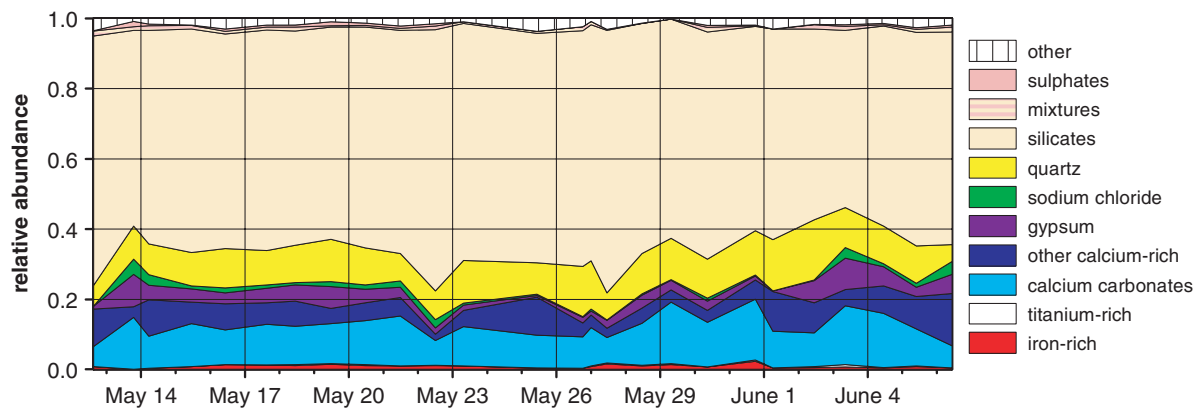

Fig. 17. Time series of chemical composition for particles between 2.5 and $10 \mu \mathrm{m}$ diameter at Tinfou ground station.

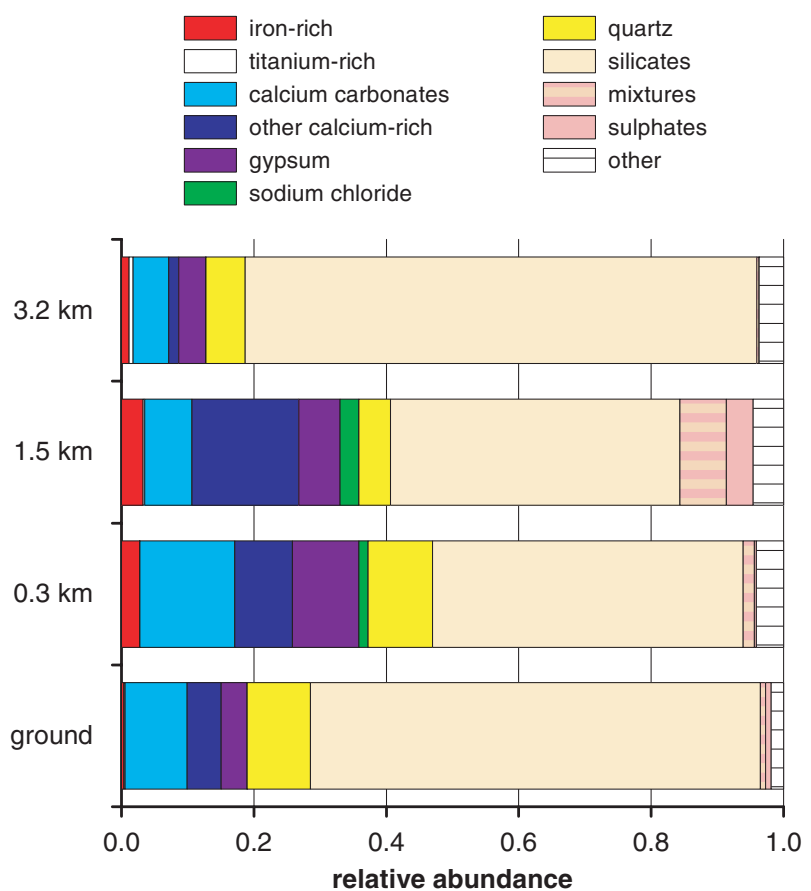

Fig. 18. Chemical composition of particles between 1 and $2.5 \mu \mathrm{m}$ diameter for different altitudes above ground (684 $\mathrm{m}$ a.s.1.) over the Tinfou region on 3 June 2006.

refractive indices - arithmetic and particle volume - weightedare shown in Table 6. The real part of the refractive index is continuously decreasing with increasing wavelength. The imaginary part mainly shows a hematite signature (cf. Sokolik and Toon, 1999), with very high absorption for wavelengths smaller than $530 \mathrm{~nm}$.

The real part of the refractive index at Tinfou is very similar to earlier measurements. For Tenerife, Barbados and the Atlantic Ocean, Patterson et al. (1977) reported values between 1.558 and 1.562 at $550 \mathrm{~nm}$ wavelength and 1.552 at $633 \mathrm{~nm}$. For Saharan dust at Cape Verde, Carlson and Caverly (1977) found values for the imaginary part of $0.018,0.008$ and 0.0029 at wavelengths of 375, 468 and $610 \mathrm{~nm}$, respectively. At Tenerife, Patterson et al. (1977) measured approximately 0.02, 0.012, 0.008 and 0.004 for wavelengths of $350,450,530$ and $670 \mathrm{~nm}$, respectively.
Table 5. Parameters of the aspect ratio density distribution function for the particle classes

\begin{tabular}{lcc}
\hline Particle class & $\sigma$ & $\mu$ \\
\hline Iron-rich & 0.5785 & -0.6573 \\
Titanium-rich & 0.6310 & -0.5818 \\
Calcium carbonates & 0.6152 & -0.4903 \\
Other calcium-rich & 0.6727 & -0.4294 \\
Gypsum & 0.6706 & -0.3695 \\
Sodium chloride & 0.6974 & -0.7682 \\
Quartz & 0.6120 & -0.5634 \\
Silicates & 0.6170 & -0.4949 \\
Sulphate silicate mix. & 0.7211 & -0.6085 \\
Sulphates & 0.6636 & -0.7594 \\
Ammonium sulphate & 0.4895 & -1.1605 \\
Total & 0.6467 & -0.5490 \\
\hline
\end{tabular}

The values found at Tinfou are approximately half of those for shorter wavelengths and about the same as those reported over the Mediterranean (0.004 at $440 \mathrm{~nm}$; Tafuro et al., 2006). For red light, however, the difference is larger. As our model incorporates hematite as the only absorbing material, our results exhibit a stronger spectral variation of the imaginary part of the refractive index as found by atmospheric measurements. This indicates that another material with an absorption less dependent on wavelength is present in the Saharan dust, which may be trace amounts of soot (Müller et al., 2008).

\section{Conclusions and summary}

Within the Saharan desert, aerosol physical and chemical properties have been measured. The full size distribution, mass concentration and mineralogical bulk composition have been measured on a daily basis. Single particle analysis was performed on approximately 74000 particles.

The total mass concentrations strongly depend on the local wind speed, indicating the local production of very large particles, which, for high wind situations, dominate the aerosol mass concentration. In contrast, the mineralogical composition of the total aerosol is fairly constant. The mass concentrations of the 


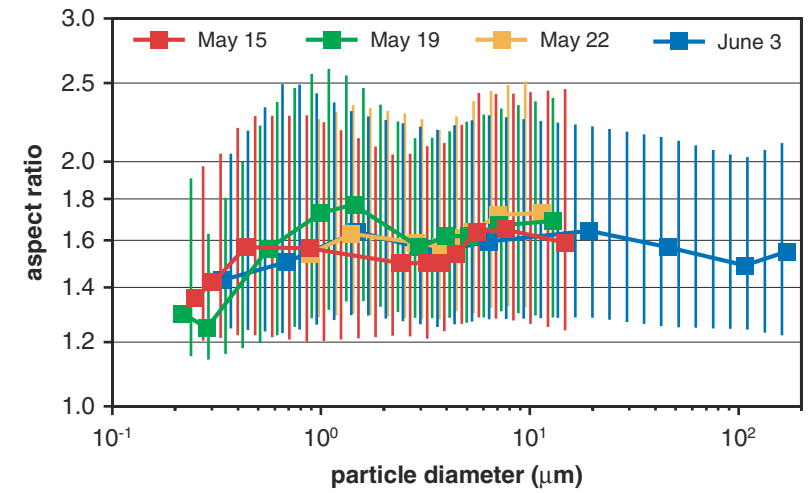

Fig. 19. Size-resolved aspect ratio for four selected days at Tinfou ground station. The shaded area shows the range between the 0.1 and 0.9 quantile.

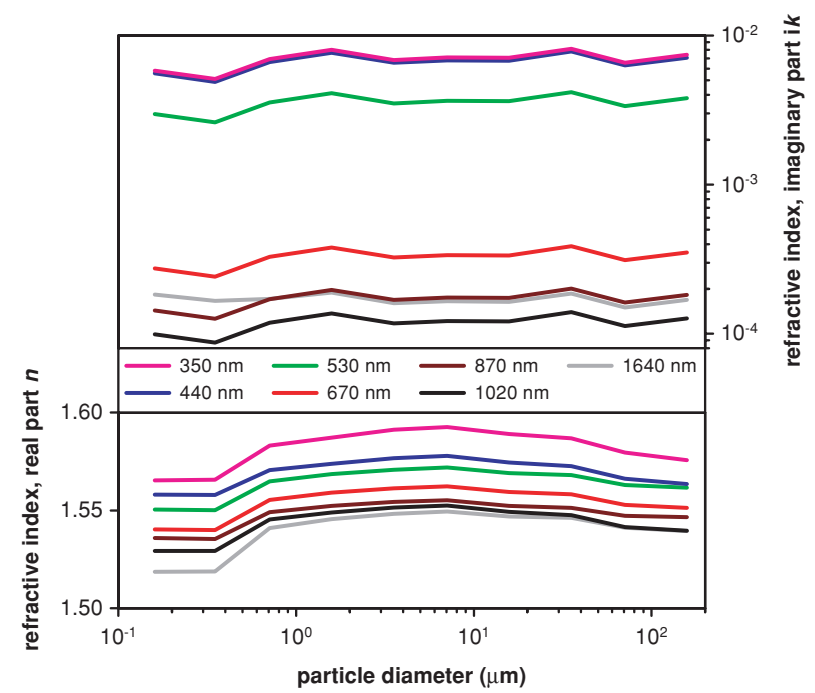

Fig. 20. Average aerosol complex refractive index for several wavelengths as function of particle diameter at Tinfou ground station.

smaller particles $\left(\mathrm{PM}_{10}\right.$ and $\left.\mathrm{PM}_{2.5}\right)$ are much less dependent on wind speed, indicating their advection and the existence of a desert background aerosol.

Three size regimes can be distinguished from a chemi$\mathrm{cal} /$ mineralogical point of view. Even in such a remote region, particles smaller than $500 \mathrm{~nm}$ are significantly influenced by anthropogenic emissions, resulting in the presence of soot and ammonium sulphate in variable abundances. For sizes larger than $500 \mathrm{~nm}$, however, the aerosol is dominated by mineral dust with a surprisingly constant composition. Main components are silicates (feldspars and clay minerals), quartz and carbonates. For larger than $50 \mu \mathrm{m}$ diameter, half of the particles consist of quartz. A very strong local source is necessary to imprint its signature in the aerosol chemical composition, which was observed once during the campaign in form of a high abundance of calcite and gypsum.

Comparison of the ground-based measurements with airborne samples shows that there usually exists a well-mixed boundary layer, as only small differences were found. For the same particle size range, the dominance of silicates is stronger in the airborne samples than in the ground-based ones. On single days, however, a strong atmospheric stratification in terms of particle composition was found.

Measurements of the particle aspect ratio show more spherical shapes for particles smaller than $500 \mathrm{~nm}$ diameter and more elongated shapes for larger particles, which can be attributed to their chemical composition and origin.

From the analysis of individual particles, it was derived that iron-rich compounds can be distributed in several different ways across the particle volume. They can occur as surface coatings, throughout the particle volume or in an intermediate state (most likely, as heterogeneous inclusions). Most of the iron detected by the single particle analysis is associated with silicates having comparatively low iron content. Only a minor amount of the total iron is found in single iron-rich particles.

From the chemical and mineralogical analysis, the complex refractive indices were derived, which are in good accordance with those calculated from other measurement techniques. However, the presence of soot, which influences the optical properties significantly, could not be quantified. This has to be left for future analysis.

\section{Acknowledgments}

This study was supported by the German Research Foundation (DFG contract FOR 539) in the framework of the research group SAMUM. Support by the Royal Government of Morocco and by

Table 6. Average complex refractive indices $(m=n+\mathrm{i} k$ ) derived from chemical measurements for different wavelengths. In the upper part, the arithmetic mean for all particle sizes is given, together with the standard deviation over particle size. In the lower part, the volume-weighted average is calculated using the medium to low dust particle size distribution (Table 4)

\begin{tabular}{lccccccc}
\hline Wavelength (nm) & 350 & 440 & 530 & 670 & 870 & 1020 & $1640 \mathrm{~nm}$ \\
\hline$n$ & $1.582 \pm 0.010$ & $1.569 \pm 0.007$ & $1.564 \pm 0.008$ & $1.554 \pm 0.008$ & $1.548 \pm 0.007$ & $1.543 \pm 0.008$ & $1.540 \pm 0.011$ \\
$k \times 10^{-3}$ & $6.9 \pm 0.9$ & $6.6 \pm 0.9$ & $3.5 \pm 0.5$ & $0.33 \pm 0.04$ & $0.17 \pm 0.02$ & $0.12 \pm 0.02$ & $0.17 \pm 0.01$ \\
$n_{\mathrm{vol}}$ & 1.579 & 1.566 & 1.563 & 1.553 & 1.548 & 1.542 & 1.541 \\
$k_{\mathrm{vol}} \times 10^{-3}$ & 7.3 & 7.0 & 3.7 & 0.34 & 0.18 & 0.12 & 0.17 \\
\hline
\end{tabular}


the governors of the provinces of Ouarzazate and Zagora is gratefully acknowledged. We also want to thank Prof. Dr. Mohammed Diouri (Laboratoire Physique Atmosphérique, Département de Physique, Faculté des Sciences, Université Mohammed 1er, Oujda, Morocco) for his support and many suggestions in preparing this field experiment. We are grateful for the extraordinary preparations of the equipment provided by Berthold Friederich and by the workshops of the IPA, Mainz. Logistic support and the operation of the Partenavia aircraft by enviscope, Frankfurt is highly acknowledged.

\section{References}

Anderson, J. R., Buseck, P. R., Patterson, T. L. and Arimoto, R. 1996. Characterization of the Bermuda tropospheric aerosol by combined individual-particle and bulk-aerosol analysis. Atmos. Environ. 30, 319-338.

Avila, A., Queralt-Mitjans, I. and Alarcón, M. 1997. Mineralogical composition of African dust delivered by red rains over northeastern Spain. J. Geophys. Res. 102, $21977-21996$.

Balkanski, Y., Schulz, M., Claquin, T. and Guibert, S. 2007. Reevaluation of Mineral aerosol radiative forcings suggests a better agreement with satellite and AERONET data. Atmos. Chem. Phys. 7, 81-95.

Barthelmy, D. 2007. Mineralogy database. Available at http://www.webmineral.com.

Bauer, S. E., Balkanski, Y., Schulz, M., Hauglustaine, D. A. and Dentener, F. 2004. Global modeling of heterogeneous chemistry on mineral aerosol surfaces: influence on tropospheric ozone chemistry and comparison to observations. J. Geophys. Res. 109, D02304.

Belyaev, S. P. and Levin, L. M. 1972. Investigation of aerosol aspiration by photographing particle tracks under flash illumination. J. Aerosol Sci. 3, 127-140.

Belyaev, S. P. and Levin, L. M. 1974. Techniques for collection of representative aerosol samples. J. Aerosol Sci. 5, 325-338.

Brindley, G. W. 1980. Quantitative X-Ray Mineral Analysis of Clays. In: Crystal Structures of Clay Minerals and their X-Ray Identification (eds. G. W. Brindley and G. Brown). Mineralogical Society, London, 411-438.

Carlson, T. N. and Caverly, R. S. 1977. Radiative Characteristics of Saharan Dust at Solar Wavelengths. J. Geophys. Res. 82, 3141-3152.

Chester, R. and Johnson, L. R. 1971. Atmospheric Dusts collected off the West African Coast. Nature 229, 105-107.

Chester, R., Elderfield, H. and Griffin, J. J. 1971. Dust transported in the North-east and South-east Trade Winds in the Atalntic Ocean. Nature 233, 474-476.

Chester, R., Elderfield, H., Griffin, J. J., Johnson, L. R. and Padgham, R. C. 1972. Eolian dust along the eastern margins of the Atlantic Ocean. Mar. Geol. 13, 91-105.

Chipera, S. J. and Bish, D. L. 2002. FULLPAT: a full-pattern quantitative analysis program for X-ray powder diffraction using measured and calculated patterns. J. Appl. Crystallogr. 35, 744-749.

Chung, F. H. 1974. Quantitative interpretation of X-ray diffraction patterns of mixtures, I: matrix-flushing method for quantitative multicomponent analysis. J. Appl. Crystallogr. 7, 519-525.

Cornelis, W. M. and Gabriels, D. 2004. A simple model for the prediction of the deflation threshold shear velocity of dry loose particles. Sedimentology 51, 39-51.
d'Almeida, G. A. 1987. On the variability of desert aerosol radiative characteristics. J. Geophys. Res. 92, 3017-3026.

d'Almeida, G. A. and Schütz, L. 1983. Number, mass and volume distributions of mineral aerosol and soils of the Sahara. J. Clim. Appl. Meteorol. 22, 233-243.

Dentener, F. J., Carmichael, G. R., Zhang, Y., Lelieveld, J. and Crutzen, P. J. 1996. Role of mineral aerosol as a refractive surface in the global troposphere. J. Geophys. Res. 101, 22 869-22 889.

Desboeufs, K. V. and Cautenet, G. 2005. Transport and mixing zone of desert dust and sulphate over Tropical Africa and the Atlantic Ocean region. Atmos. Chem. Phys. Discuss. 5, 5615-5644.

Draxler, R. R. and Hess, G. D. 1998. An overview of the HYSPLIT_4 modelling system for trajectories, dispersion and deposition. Aust. Meteorol. Mag. 47, 295-308.

Dubovik, O., Holben, B., Eck, T. F., Smirnov, A., Kaufman, Y. J. and co-authors. 2002. Variability of absorption and optical properties of key aerosol types observed in worldwide locations. J. Atmos. Sci. 59, 590-608.

Dubovik, O., Sinyuk, A., Lapyonok, T., Holben, B. N., Mishchenko, M. and co-authors. 2006. Application of spheroid models to account for aerosol particle nonsphericity in remote sensing of desert dust. J. Geophys. Res. 111, D11208, available at http://aeronet.gsfc.nasa.gov/new_web/optical_properties.html.

Eissa, N. A., Gomaa, S. S., Hassaan, M. Y. and Sallam, H. A. 1988. Mössbauer, X-ray and derivatographic studies on Egyptian Nile clay. Hyperfine Interact. 41, 775-778.

Eyre, J. K. and Dickson, D. P. E. 1995. Mössbauer spectroscopy analysis of iron-containing minerals in the Chinese loess. J. Geophys. Res. 100B, 17 925-17930.

Falkovich, A. H., Ganor, E., Levin, Z., Formenti, P. and Rudich, Y. 2001. Chemical and mineralogical analysis of individual mineral dust particles. J. Geophys. Res. 106, 18 029-18 036.

Gillette, D. A. and Nagamoto, C. 1993. Size distribution and single particle composition for two dust storms in Soviet central Asia in September 1989 and size distribution and chemical composition of local soil. In: Joint Soviet-American Experiment on Arid Aerosol (eds. G. S. Golitsyn, D. A. Gillette, T. Johnson, V. N. Ivanov, S. M. Kolomiyets, and co-editors). Hydrometeoizdat, St. Petersburg, 135-146.

Glaccum, R. A. and Prospero, J. M. 1980. Saharan aerosols over the tropical north Atlantic-mineralogy. Mar. Geol. 37, 295-321.

Goudie, A. S. and Middleton, N. J. 2001. Saharan dust storms: nature and consequences. Earth-Sci. Rev. 56, 179-204.

Guerzoni, S., Molinaroli, E. and Chester, R. 1997. Saharan dust inputs to the western Mediterranean Sea: depositional patterns, geochemistry and sedimentological implications. Deep-Sea Res. II 44, 631-654.

Haywood, J. and Boucher, O. 2000. Estimated of the direct and indirect radiative forcing due to tropospheric aerosols: a review. Rev. Geophys. 38, 513-543.

Heintzenberg, J. 2008. The SAMUM-1 experiment over Southern Morocco: overview and introduction. Tellus 61B, doi:10.1111/j.16000889.2008.00403.x.

Helmert, J., Heinold, B., Tegen, I., Hellmuth, O. and Wendisch, M. 2007. On the direct and semidirect effects of Saharan dust over Europe: a modeling study. J. Geophys. Res. 112, D13208.

Hess, M., Koepke, P. and Schult, I. 1998. Optical properties of aerosols and clouds: the software package OPAC. Bull. Am. Met. Soc. 79, 831-844. 
Hillier, S. and Velde, B. 1991. Octahedral occupancy and the chemical composition of diagenetic (low-temperature) chlorites. Clay Mineral. 26, 149-168.

ICDD. 2002. Powder Diffraction File PDF-2. JCPDS - International Center for Diffraction Data, Newton Square, PA, USA.

Iversen, J. D. and White, B. R. 1982. Saltation threshold on Earth, Mars and Venus. Sedimentology 29, 111-119.

Ivlev, L. S. and Popova, S. I. 1972. Optical constants of substances of atmospheric aerosol. Izv. Vuz. Fiz. 5, 91-97.

Iwasaka, Y., Shi, G.-Y., Yamada, M., Matsuki, A., Trochkine, D., and co-authors. 2003. Importance of dust particles in the free troposphere over the Taklamakan Desert: electron microscopic experiments of particles collected with a balloonborne particle impactor at Dunhaug, China. J. Geophys. Res. 108, doi:10.1029/2002JD3270.

Jacobson, M. Z. 2001. Global direct radiative forcing due to multicomponent anthropogenic and natural aerosols. J. Geophys. Res. 106, 1551-1568.

Jaenicke, R. 1983. Aerosol physical properties. In: Report of the Experts Meeting on Aerosols and Their Climatic Effects (eds. A. Deepak and H. E. Gerber). International Council of Scientific Unions/World Meteorological Organization, Williamsburg, VA, 17-31.

Jaenicke, R. 1988. Aerosol physics and chemistry. In: LandoltBörnstein: Numerical Data and Functional Relationships in Science and Technology (ed. G. Fischer). Springer, New York, 391-457.

Jaenicke, R. and Junge, C. 1967. Studien zur oberen Grenzgröße des natürlichen Aerosols. Beitr. Phys. Atmos./Contrib. Atmos. Phys. 40, 129-143.

Jeong, G.-R. and Sokolik, I. N. 2007. Effect of mineral dust aerosols on the photolysis rates in the clean and polluted marine environments. $J$. Geophys. Res. 112, D21308.

Kaaden, N., Maßling, A., Schladitz, A., Müller, T., Kandler, K. and coauthors. 2008. State of mixing, shape factor, number size distribution, and hygroscopic growth of the Saharan anthropogenic and mineral dust aerosol at Tinfou, Morocco. Tellus 61B, doi:10.1111/j.16000889.2008.00388.x.

Kandler, K., Benker, N., Bundke, U., Cuevas, E., Ebert, M. and coauthors. 2007. Chemical composition and complex refractive index of Saharan Mineral Dust at Izaña, Tenerife (Spain) derived by electron microscopy. Atmos. Environ. 41, 8058-8074.

Karickhoff, S. W. and Bailey, G. W. 1973. Optical absorption spectra of clay minerals. Clay Clay Miner. 21, 59-70.

Kaufman, Y. J., Koren, I., Remer, L. A., Tanré, D., Ginoux, P. and co-authors. 2005. Dust transport and deposition observed from the Terra-Moderate Resolution Imaging Spectroradiometer (MODIS) spacecraft over the Atlantic Ocean. J. Geophys. Res. 110, doi:10.1029/2003JD004436.

Kiefert, L., McTainsh, G. H. and Nickling, W. G. 1996. Sedimentological characteristics of Saharan and Australian Dusts. In: The Impact of Desert Dust Across the Mediterranean (eds. S. Guerzoni and R. Chester). Kluwer Academic Publishers, Dordrecht, 183-190.

Knippertz, P., Ansmann, A., Althausen, D., Müller, D., Tesche, M. and co-authors. 2008. Dust Mobilization and Transport in the Northern Sahara during SAMUM 2006 - A Meteorological Overview. Tellus 61B, doi:10.1111/j.1600-0889.2008.00380.x.

Lafon, S., Rajot, J.-L., Alfaro, S. C. and Gaudichet, A. 2004. Quantification of iron oxides in desert aerosol. Atmos. Environ. 38, 12111218.
Lafon, S., Sokolik, I. N., Rajot, J. L., Caquineau, S. and Gaudichet, A. 2006. Characterization of iron oxides in mineral dust aerosols: implications for light absorption. J. Geophys. Res. 111, D21207.

Lesins, G., Chylek, P. and Lohmann, U. 2002. A study of internal and external mixing scenarios and its effect on aerosol optical properties and direct radiative forcing. J. Geophys. Res. 107, D04094.

Levin, Z., Ganor, E. and Gladstein, V. 1996. The effects of desert particles coated with sulfate on rain formation in the Eastern Mediterranean. J. Appl. Meteorol. 35, 1511-1523.

Marple, V. A. and Willeke, K. 1976. Impactor design. Atmos. Environ. 10, 891-896.

Marticorena, B. and Bergametti, G. 1995. Modeling the atmospheric dust cycle, 1: design of a soil-derived dust emission scheme. J. Geophys. Res. 100, 16415-16430.

Matsuki, A., Iwasaka, Y., Shi, G., Zhang, D., Trochkine, D. and coauthors. 2005. Morphological and chemical modification of mineral dust: observational insight into the heterogeneous uptake of acidic gases. Geophys. Res. Lett. 32, L22806.

Matthias-Maser, S. 1999. MOCIS, an automatic mobile cascade impaction system developed for use at ground and on airborne platforms and suitable for single particle analysis. J. Aerosol Sci. 30, S367S368.

May, K. R. and Clifford, R. 1967. The impaction of aerosol particles on cylinders, spheres, ribbons and discs. Ann. Occup. Hyg. 10, 83-95.

Mikami, M., Leys, J., Ishizuka, M., Yamada, Y. and Heidenreich, S. 2007. Multi-size saltation process from fallow-wheat-field in Australia during JADE IOP. In: Proceedings of the IAMAS/IUGG 2007, Perugia, Italy .

Mikami, M., Yamada, Y., Ishizuka, M., Ishimaru, T., Gao, W. and coauthors. 2005. Measurement of saltation process over gobi and sand dunes in the Taklimakan desert, China, with newly developed sand particle counter. J. Geophys. Res. 110, D18S02.

Moore, D. M. and Reynolds, R. C. J. 1997. X-Ray Diffracton and the Identification and Analysis of Clay Minerals. Oxford University Press, Oxford, New York .

Murayed, Y., Kuzmann, E. and Vértes, A. 2000. Mössbauer and X-ray investigation of clay minerals originated from Lybia. J. Radioanal. Nucl. Ch. 246, 379-384.

Müller, T., Schladitz, A., Maßling, A., Kaaden, N., Wiedensohler, A. and co-authors. 2008. Spectral absorption coefficients and imaginary parts of refractive indices of Saharan dust during SAMUM-1. Tellus 61B, doi:10.1111/j.1600-0889.2008.00399.x.

O'Hara, S. L., Clarke, M. L. and Elatrash, M. S. 2006. Field measurements of desert dust deposition in Libya. Atmos. Environ. 40, 3881-3897.

Patterson, E. M., Gillette, D. A. and Stockton, B. H. 1977. Complex index of refraction between 300 and $700 \mathrm{~nm}$ for Saharan aerosols. J. Geophys. Res. 82, 3153-3160.

Petzold, A., Rasp, K., Weinzierl, B., Esselborn, M., Hamburger, T. and co-authors. 2008. Saharan dust absorption and refractive index from aircraft-based observations during SAMUM 2006. Tellus 61B, doi:10.1111/j.1600-0889.2008.00383.x.

Philipp, H. R. 1985. Silicon Dioxide $\left(\mathrm{SiO}_{2}\right)$, Type $\alpha$ (Crystalline). In: Handbook of Optical Constants of Solids I (ed. E. D. Palik). Academic Press, New York, 719-747.

Rasband, W. S. 2006. ImageJ. U. S. National Institutes of Health, Bethesda, Maryland, USA . Available at http://rsb.info.nih.gov/ij/. 
Rastogi, N. and Sarin, M. M. 2006. Chemistry of aerosols over a semiarid region: evidence for acid neutralization by mineral dust. Geophys. Res. Lett. 33, L23815.

Reid, J. S., Jonsson, H. H., Maring, H. B., Smirnov, A., Savoie, D. L. and co-authors. 2003. Comparison of size and morphological measurements of coarse mode dust particles from Africa. J. Geophys. Res. 108, 8593 .

Rutledge, G. K., Alpert, J. and Ebuisaki, W. 2006. NOMADS: a climate and weather model archive at the National Oceanic and Atmospheric Administration. Bull. Am. Meteorol. Soc. 87, 327-341. Available at ftp://www.arl.noaa.gov/pub/archives/fnl/.

Schladitz, A., Müller, T., Maßling, A., Kaaden, N., Kandler, K. and coauthors. 2008. In situ measurements of optical properties at Tinfou (Morocco) during the Saharan Mineral Dust Experiment SAMUM 2006. Tellus 61B, doi:10.1111/j.1600-0889.2008.00397.x.

Schütz, L. 1989. Atmospheric mineral dust-properties and source markers. In: Paleoclimatology and Paleometeorology: Modern and Past Patterns of Global Atmospheric Transport (eds. M. Leinen and M. Sarnthein). Kluwer Academic Publishers, Dordrecht, 359-383.

Schütz, L. and Jaenicke, R. 1974. Particle number and mass distributions above $10^{-4} \mathrm{~cm}$ radius in sand and aerosol of the Sahara Desert. J. Appl. Meteorol. 13, 863-870.

Schütz, L. and Sebert, M. 1987. Mineral aerosols and source identification. J. Aerosol Sci. 18, 1-10.

Shettle, E. P. 1984. Optical and radiative properties of a desert aerosol model. In: IRS '84: Current Problems in Atmospheric Radiation (ed. G. Fiocco). Deepak Publishing, Hampton, 74-77.

Sokolik, I. N. and Toon, O. B. 1999. Incorporation of mineralogical composition into models of the radiative properties of mineral aerosol from UV to IR wavelengths. J. Geophys. Res. 104, 9423-9444.

Sokolik, I. N., Winker, D. M., Bergametti, G., Gillette, D. A., Carmichael, G. and co-authors. 2001. Introduction to special section: outstanding problems in quantifying the radiative impacts of mineral dust. J. Geophys. Res. 106, 18 015-18027.
Sullivan, R. C., Guazzotti, S. A., Sodeman, D. A. and Prather, K. A. 2007. Direct observations of the atmospheric processing of Asian mineral dust. Atmos. Chem. Phys. 7, 1213-1236.

Tafuro, A. M., Barnaba, F., De Tomasi, F., Perrone, M. R. and Gobbi, G. P. 2006. Saharan dust particle properties over the central Mediterranean. Atmos. Res. 81, 67-93.

Tegen, I., Lacis, A. A. and Fung, I. 1996. The influence of mineral aerosols from disturbed soils on the global radiaton budget. Nature 380, 419-422.

Tropf, W. J. 1998. Calcium carbonate, Calcite $\left(\mathrm{CaCO}_{3}\right)$. In: Handbook of Optical Constants of Solids III (ed. E. D. Palik). Academic Press, New York, 701-715.

Tsoar, H. and Pye, K. 1987. Dust transport and the question of desert loess formation. Sedimentology 34, 139-153.

VDI. 1997. Measurement of Particulate Precipitations-Microscopic differentiation and size Fractionated Determination of Particle Deposition on Adhesive Collection Plates-Sigma-2 sampler. Guideline 2119, Sheet 4. Beuth Verlag, Berlin.

Warner, T. T. 2004. Desert Meteorology. Cambridge University Press, Cambridge .

Weinzierl, B., Petzold, A., Esselborn, M., Wirth, M., Rasp, K. and coauthors. 2008. Airborne measurements of dust layer properties, particle size distribution and mixing state of Saharan dust during SAMUM 2006. Tellus 61B, doi:10.1111/j.1600-0889.2008.00392.x.

Wiegner, M., Gasteiger, J., Kandler, K., Weinzierl, B., Rasp, K. and coauthors. 2008. Numerical simulations of optical properties of Saharan dust aerosols with emphasis on linear depolarization ratio. Tellus 61B, doi:10.1111/j.1600-0889.2008.00381.x.

Winker, D. M., Couch, R. H. and McCormick, M. P. 1996. An overview of LITE: NASA's lidar in-space technology experiment. Proc. IEEE 84, 164-180.

Zorn, S. 2005. Optimierung des "Mobile Cascade Impaction System" für den Einsatz in ariden Gebieten. Diploma thesis. Institute for Atmospheric Physics, Johannes-Gutenberg-University, Mainz. 